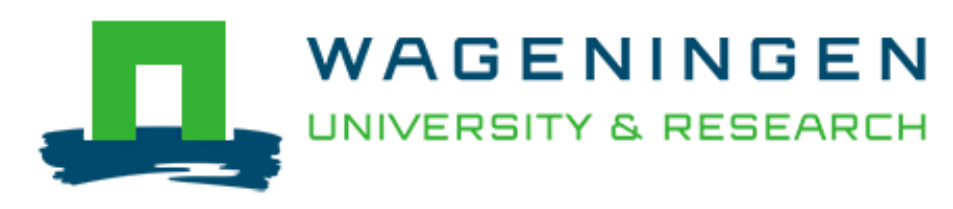

Analysing social-ecological interactions in disease control: An agent-based model on farmers' decision making and potato late blight dynamics

Pacilly, F. C. A., Hofstede, G. J., Lammerts van Bueren, E. T., \& Groot, J. C. J.

This is a "Post-Print" accepted manuscript, which has been Published in "Environmental Modelling and Software"

This version is distributed under a non-commercial no derivatives Creative Commons (c) (1) (8) reproduction in any medium, provided the original work is properly cited and not used for commercial purposes. Further, the restriction applies that if you remix, transform, or build upon the material, you may not distribute the modified material.

Please cite this publication as follows:

Pacilly, F. C. A., Hofstede, G. J., Lammerts van Bueren, E. T., \& Groot, J. C. J. (2019). Analysing social-ecological interactions in disease control: An agent-based model on farmers' decision making and potato late blight dynamics. Environmental Modelling and Software, 119, 354-373. https://doi.org/10.1016/j.envsoft.2019.06.016

You can download the published version at:

https://doi.org/10.1016/j.envsoft.2019.06.016 


\title{
Analysing social-ecological interactions in disease control: An agent-based model on farmers' decision making and potato late blight dynamics
}

Francine C.A. Pacilly ${ }^{* 1}$, Gert Jan Hofstede ${ }^{2}$, Edith T. Lammerts van Bueren ${ }^{3}$ and Jeroen C.J. Groot ${ }^{1}$ ${ }^{1}$ Wageningen University \& Research, Farming Systems Ecology, P.O. Box 430, 6700 AK Wageningen, The Netherlands.

${ }^{2}$ Wageningen University \& Research, Information Technology, P.O. Box 8130, 6700 EW Wageningen, The Netherlands.

${ }^{3}$ Wageningen University \& Research, Plant Breeding, P.O. Box 386, 6700 AJ Wageningen, The Netherlands.

*Corresponding author: francine.pacilly@gmail.com

\begin{abstract}
In this paper we focus on potato late blight control in the Netherlands to analyse the social-ecological interactions between farmer behaviour and disease dynamics. An agent-based model was developed to analyse the use of crop resistance for sustainable disease control. The framework on farmers' decision-making was based on a behavioural theory and supported by data from literature and interviews with Dutch potato farmers. This framework was integrated with a previously developed spatially explicit model on potato late blight dynamics. We assumed a scenario where a new resistant potato variety was introduced to the market. The model reproduced a boom-and-bust cycle: the percentage of farmers growing the resistant variety increased until resistance breakdown occurred by emergence and spread of a virulent strain, and in response farmers switched to other potato varieties and management strategies. Several factors and processes were identified that could contribute to the development of sustainable disease management strategies.
\end{abstract}

Keywords: Phytophthora infestans, social-ecological systems, resistance management, Consumat

\section{Introduction}

One of the main challenges in global food production is to control upcoming pests and diseases (Mack et al., 2000). Examples of emerging infectious diseases of crops include Banana Xanthomonas Wilt and wheat rust (Vurro et al., 2010). These diseases can have huge impacts on human well-being, economy and biodiversity. Control of the disease is the result of an interplay between pathogens, hosts and actors (e.g. farmers, governments and researchers). The actors in the system can have divergent approaches in disease control as a result of different perspectives and objectives. In this paper we focus on potato late blight control to analyse interactions between farmer behaviour and disease dynamics. Phytophthora infestans, the causal agent of late blight, first arrived in Europe in 
1845 where it was responsible for the Irish potato famine in which one million people died and another one million people emigrated. $P$. infestans has a high evolutionary potential and as new strains evolve, also new outbreaks of the disease emerge, causing devastating epidemics globally (Anderson et al., 2004). Because the disease is dispersed by wind, control strategies should be analysed at the landscape level. In this project we focus on the Netherlands which is a large producer of seed, ware and starch potatoes (Haverkort et al., 2008). The high potato density and favourable weather conditions for the disease (moderate temperatures and high humidity) result in frequent outbreaks of the disease. Currently the use of fungicides is the most important control method but these are harmful for the environment. The use of resistant varieties could improve sustainability of late blight management; however, as a result of pathogen adaptation new virulent strains can emerge resulting in resistance breakdown.

Previously we described late blight management in potato production as a social-ecological system which is driven by interrelated social and biophysical processes that interact across multiple temporal and spatial scales (Pacilly et al., 2016). Since the disease incidence in the landscape is influenced by biophysical processes as well as crop management strategies, it is important to focus not only on epidemiological processes but also on decision-making concerning disease management. In this system farmers play a key role since they decide on crop management. Their management strategies affect the disease pressure in a landscape and the sustainability in terms of environmental pollution and breakdown of disease-resistance, which can be considered as a common good. Secondly, farmers also respond to conditions, influences and changes in the socio-institutional setting (e.g., policies, markets, extension and peer-to-peer communication) and the biophysical environment (e.g., soil and weather), and they adapt their management strategies based on past experiences. Therefore, to identify effective and sustainable late blight management strategies, it is important to consider the social-ecological interactions.

Previously we described the social-ecological system of potato late blight and used modelling for analysing the effect of management strategies on disease control (Pacilly et al., 2016; Pacilly et al., 2018). Model scenarios were discussed in workshops with farmers (Pacilly et al., 2019). Section 1.1 describes the findings from previous work. In this paper we focus on the social-ecological interactions by adding the dimension of decision making by multiple, interacting farmers in a landscape in the model. Exploring the interactions and feedback mechanisms related to farmers' decision making and late blight dynamics can increase understanding of the system behaviour and contribute to the development of effective management strategies and policies. Agent-based modelling was used to simulate the social-ecological interactions. Agent-based models have been recognized as a useful tool to analyse human decision-making in a spatial environment in which biophysical processes occur (An, 2012). Agent-based models consist of heterogeneous entities which 
interact with each other and the environment and is therefore very suitable for simulating individual decision-making agents. This is very relevant in the context of agricultural systems where individual households are the main decision makers but can strongly differ. Agent-based modelling can therefore contribute to improved understanding of farmers' behaviour in response to changing environmental, economic, or institutional conditions (Huber et al., 2018). Furthermore farm management includes both short and long term decisions. For example, decisions on crop selection are made yearly as a result of annual production cycles while the use of inputs such as fungicides or fertilizers are made on a daily basis during the growing season. Also with respect to disease dynamics processes occur at different temporal scales. Disease is spread during the growing season but breakdown of resistance can take multiple years. Both short and long term processes are important characteristics of the system. Agent-based modelling is a useful tool for simulating and analysing these complex interactions at different scales.

During the last decades, the number of studies using agent-based modelling to couple social and natural systems has rapidly increased. Reviews on the use of models in social-ecological systems research are provided by An (2012), Filatova et al. (2013), Matthews et al. (2007), Parker et al. (2003) and Schlüter et al. (2012). One of the challenges that was identified includes the integrating of social and ecological systems (Parker et al., 2008). The number of models that is able to simulate two-way feedbacks between human and environmental subsystems are scarce while this is essential for studying non-linear interactions between human and natural systems (Filatova et al., 2016). In this study we aim to contribute to this field of research by developing a model framework which integrates farmer behaviour and disease dynamics.

To simulate human behaviour, several methods have been used. When data on decision making is scarce or missing, theories can be used and the implications can be confronted with empirical data (Groeneveld et al., 2017). The most common theory to simulate human behaviour is to assume rational decision making, also referred to as the homo economicus (Groeneveld et al., 2017; Schlüter et al., 2017). According to this theory agents have perfect knowledge and make calculations to identify the optimal decision that maximizes their utility or profit. However, studies on farmer behaviour have shown that farmers are also influenced by many other factors such as peer networks, individual preferences and culture (Austin et al., 1998; Edwards-Jones, 2006; Willock et al., 1999). In recent years, agent-based models have become more popular for modelling agricultural systems and the impact of policies (Groeneveld et al., 2017, Huber et al., 2017). However, there is need for improved representation of farmers' heterogeneous decision making. For models to be relevant tools for policy assessment better understanding of farmers' decision-making is needed (Reidsma et al., 2018). Current European agricultural agent-based models lack consideration of values, social interactions, norm consideration, and learning in farmers' decision-making (Huber et 
al., 2017). Furthermore the representation should consider the socioeconomic and natural environment as well as farm household characteristics. In our study we used the Consumat approach to simulate farmers' decision making on late blight management (Jager and Janssen, 2012; Jager et al., 2000; Janssen and Jager, 2001). This framework was selected to develop more behaviourally rich agents. The Consumat approach includes elements which have been recognized as important factors influencing farmers' decision making such as social interactions through a network. It also allows the implementation of a heterogeneous farmer population. The framework was first developed to explore consumer behaviour, but is now widely used in many fields of research including farmers' decision making (Malawska and Topping, 2016; Speelman, 2014; Van Duinen et al., 2016). The Consumat approach incorporates aspects from a range of behavioural theories such as theories on human needs, motivational processes, social comparison theory, social learning theory and reasoned action theory. According to the Consumat approach agents engage in different behavioural strategies dependent on their level of satisfaction and uncertainty. These behavioural strategies are repetition, imitation, optimization and social comparison (Figure 1). The advantage of the Consumat approach is that it is a highly formalized theory which allows easy implementation in an agent-based model and only few assumptions have to be made.

The framework was combined with the previously developed ecological model to simulate the use of crop resistance in disease control by analysing the adoption of the resistant variety by farmers and the durability of resistance over time. Therefore, we assumed a scenario in which a new resistant variety is introduced to the market. Previously we described that acceptance of resistant varieties is low because these varieties do not yet meet all the requirements of farmers and retailers (Pacilly et al., 2016). In the model this was reflected in a lower yield level of the resistant variety. The purpose of the model is to explore the social-ecological interactions to identify factors that could be important in the development of sustainable disease management strategies. We explored several scenarios that could affect the selection of management strategies by farmers and consequently, resistance durability. In the following sections we present a more detailed description of the model, the scenario analysis and the results. In the discussion we evaluate the model findings, the implications for disease management and steps for further research.

\subsection{Previous work}

In a previous study, we developed a model to analyse the interactions between late blight management strategies, disease dynamics and the abiotic environment at landscape level (Pacilly et al., 2018). The model was used to show opportunities and risks related to the use of plant resistance in disease control. Growing a resistant variety can reduce disease incidence in the landscape; however, in the long run resistance breakdown was observed by emergence of a new virulent strain 
due to pathogen adaptation. The durability of resistance was affected by the fraction of resistant fields in the landscape and it was found that low $(<0.2)$ as well as high $(>0.8)$ proportions of resistant fields could increase resistance durability. According to the dispersal-scaling hypothesis disease dispersal is affected by habitat size and dispersal distance, where an increase in habitat size is described as a 'positive dispersal force' and an increase in dispersal distance as a 'negative dispersal force' (Skelsey et al., 2013). A larger fraction of resistant fields means a lower fraction of susceptible fields which results in a lower disease incidence in the landscape and reduces the risk that virulent spores emerge. Virulent spores are the result of mutations during spore production in infections in susceptible fields. However, with higher fractions of resistant fields virulent spores also have an increased chance of arriving in these fields because of a lower dispersal distance between susceptible and resistant fields. As a result of the interactions between dispersal distance and habitat size, the risk on infections in resistant fields is highest with about equal proportions of susceptible and resistant fields in the landscape.

The previously developed model was adapted and used in workshops with conventional and organic farmers to demonstrate and discuss the potential role of resistant varieties for effective and sustainable control of late blight (Pacilly et al., 2019). Several scenarios were presented that showed the use of crop resistance and fungicide application in disease control at the landscape level. Farmers that attended the workshops were able to recognize the processes and patterns emerging from the model. The use of model-based scenarios in workshops was very useful to increase farmers' knowledge of the system and served as a good starting point for discussions among participants.

\section{Material and methods}

An agent-based model was developed to simulate processes on crop growth, disease dynamics and farmer interactions and decision-making on disease management in an agricultural landscape over time. The model can be described as a so-called midrange model: the aim is neither to exactly model the situation in a certain region, nor to make a purely theoretical point (Gilbert, 2008). The purpose of the model is to increase understanding of the system behaviour rather than making predictions for the future. This study is a first step in the development of a social-ecological model on late blight control. In this model version we focus on the integration of model components but the individual processes were kept as simple as possible. In future research the model processes could be further extended. Steps for further research are described in the discussion (Section 4.6). The model was implemented in NetLogo version 5.2.0 (Wilensky, 1999). A version of the model is available on the OpenABM website (http://www.openabm.org). Below we present an overview of the model with a description of the main model processes. A detailed description of the model following the ODD protocol (Overview, Design, Details) can be found in Appendix A (Grimm et al., 2006; Grimm et al., 
2010). For detailed information on the epidemiological framework, we refer to Pacilly et al. (2018).

The framework on farmers' decision-making was based on the Consumat approach (Jager and Janssen, 2012; Jager et al., 2000; Janssen and Jager, 2001) and supported by data from literature and interviews with Dutch potato farmers. In total 25 farmers were interviewed including 18 conventional and 7 organic farmers (Pacilly et al., 2016). Semi-structured interviews were carried out on topics such as general farm characteristics, the social network, late blight management strategies and the use of late blight resistant varieties. As a result of the semi-structured interviews only qualitative data was available. The main results are described in Pacilly et al. (2016). In the model description (Section 2.1) we refer to the interviews when the data supports the model framework. Furthermore data from the interviews was used to validate the model results which is described in the discussion (Section 4).

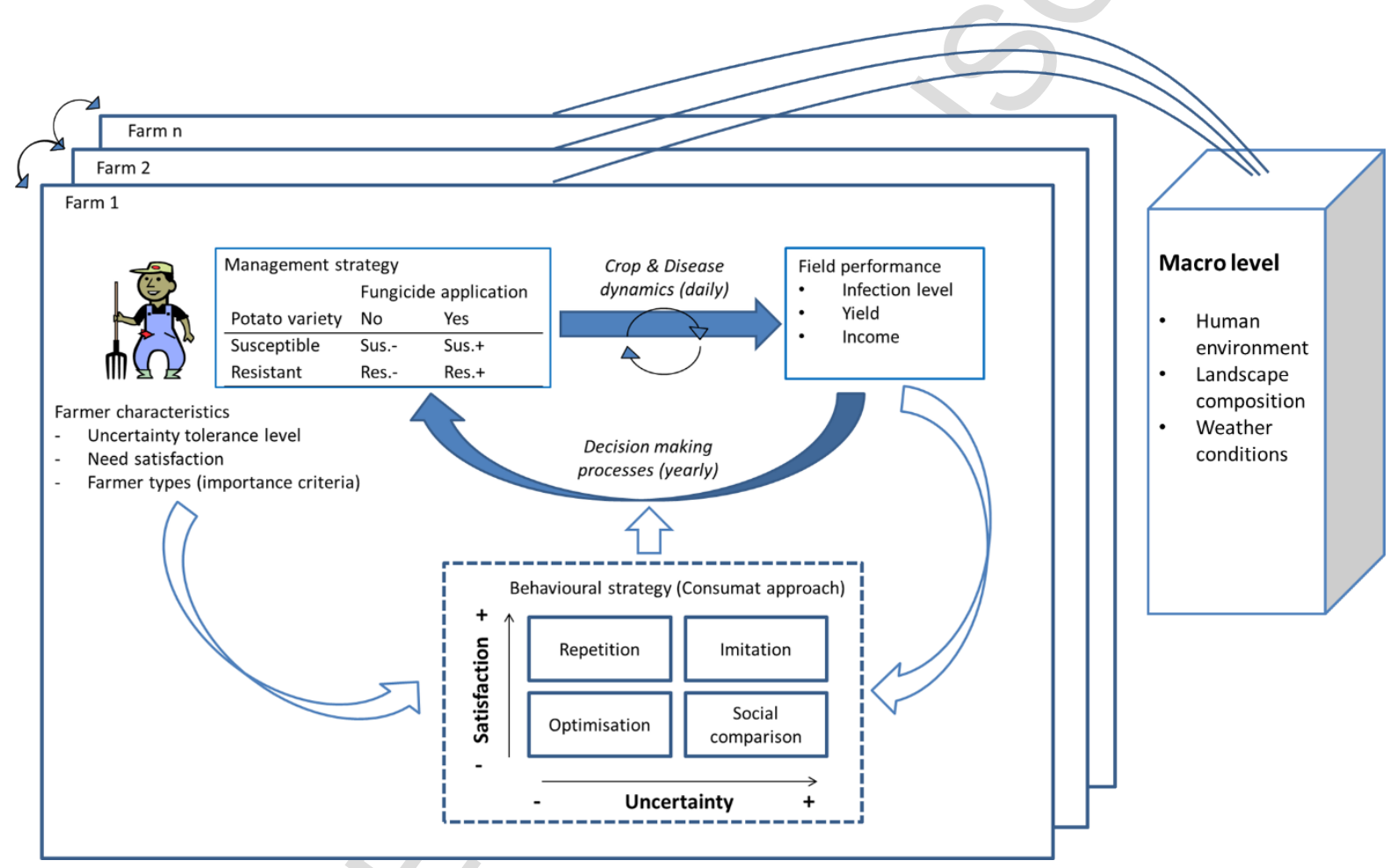

Figure 1. Conceptual overview of the model. Coloured arrows represent model processes and white arrows represent variables and frameworks used as input. Four management strategies are distinguished in the model: susceptible potato variety without fungicide application (sus-), susceptible variety with fungicide application (sus+), resistant variety without fungicide application (res-) and resistant variety with fungicide application (rest). 


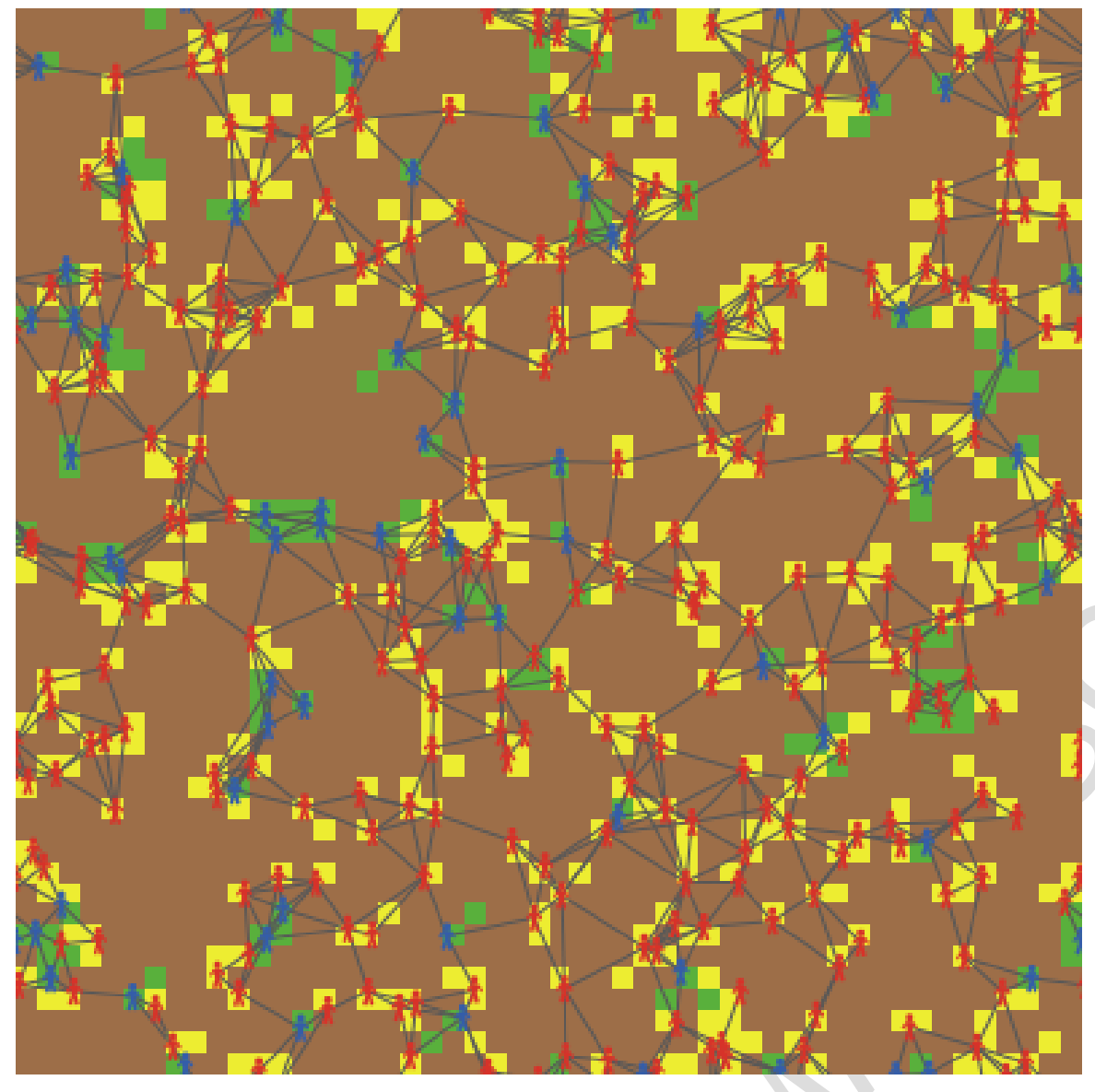

Figure 2. An example of the model landscape after 50 years of simulation. In this example the resistance remained effective. The model consists of farmers that each manage one potato field. Green and yellow grid cells represent resistant and susceptible potato fields, respectively. The brown area represents arable land with crops other than potato. The colour of the farmers shows if fungicides are applied: red = with fungicides, blue = without fungicides. The lines between farmers represent the social network among farmers. For the interpretation of the references to colour, the reader is referred to the web version of this article.

\subsection{Model description}

\subsubsection{Model Overview}

The model represents a square agricultural landscape of $10 \mathrm{~km} \times 10 \mathrm{~km}$ (Figure 2). The potato density $(24 \%)$ and the mean field size ( $\pm 7 \mathrm{ha}$ ) were derived from landscape data of an agricultural region in the Netherlands (the Noordoostpolder) and these parameters were used as input for the model. The grid cells represent a square area of $200 \mathrm{~m} \times 200 \mathrm{~m}$ (4 ha), and are clustered in agricultural fields. Crop rotation was not included in the model. Crop rotation can affect the number of initial infections, however, in the model the fraction of initial infected potato fields was kept constant between years. The spatial location of infections were randomly selected, which reflects randomizing the location of potato fields as a result of crop rotation. The model is populated by 350 farmers each of whom manages one potato field. A network was initialised in which farmers are connected to the closest 
farmers around them (shortest spatial distance). Farmers use one of the following late blight management strategies: they can grow a susceptible or resistant late blight potato variety with or without the use of fungicides. These strategies have different effects on field and landscape performance. Field performance is analysed for criteria: infection level, yield and income. Landscape performance also relates to disease dispersal and resistance durability. A conceptual overview of the model is shown in Figure 1.

We simulate the growing season from May 1 to September 30 for 50 years. Crop growth and disease dynamics are updated at a daily time step. At the end of each growing season farmers analyse their field performance and select a management strategy for the following year. The decision-making framework to select a management strategy is based on the Consumat approach (Jager and Janssen, 2012; Janssen and Jager, 2001). Based on their field performance farmers determine their satisfaction and uncertainty level which results in one of the following behavioural strategies: repetition, imitation, optimisation or social-comparison (see Section 2.1.5). The decisionmaking process is influenced by personal characteristics including their need satisfaction and uncertainty tolerance level. Four farmer types are distinguished which differ in the weights assigned to the criteria (Table 1). The weights represent the importance of the different criteria to the farmer. Interaction between farms is related to social interaction with respect to farmers' decision making and spatial interactions related to disease dispersal.

Crop growth and late blight dynamics are simulated at grid cell level. We consider only one susceptible variety and one resistant potato variety (with a single resistance gene). In our model we assume the resistant variety has a lower potential yield compared to the susceptible variety, which is reflected in the crop growth parameters. Late blight resistant potato varieties currently available on the market have a moderate yield level, however the yield potential may increase in the future with the introduction of new resistant varieties (Bionext, 2017). At the start of each growing season the infection is initialised in a fraction of the potato grid cells, randomly selected. When a grid cell is infected, spores are produced that are dispersed to nearby cells up to a distance of $1000 \mathrm{~m}$ where they can cause infections. Two types of late blight are distinguished: the wild-type and the virulent strain. The wild-type can only infect the susceptible variety, while a virulent strain can also infect the resistant variety. At the start of the simulation only the wild-type is present. The virulent strain may emerge during the growing season as the result of mutations during spore production. The ratio between the wild type and virulent strain at the end of the growing season was used to calculate the number of initial infections of the wild type and virulent strain in the following year.

Since late blight development and crop growth are weather dependent, we used measured weather data from May 1 to September 30 (152 days) for 36 years (1981-2016) as model input. These years represent variable weather conditions for crop growth and late blight dynamics. To 
simulate crop growth, mean daily temperature and total radiation was calculated and used as input for the model. Secondly, based on calculation rules using hourly temperature and relative humidity during a 24-hour period, we determined whether a day was suitable for sporangia to cause infection (Skelsey et al., 2009). Expansion of existing lesions occurs every time step but new infections as a result of spore germination can only occur on so-called 'blight days'. For more details we refer to Pacilly et al. (2018). At the start of each year a dataset is randomly selected out of these 36 years of weather data.

Table 1. Overview of farmer types in the model which differ in the weights assigned to the criteria on infection level, potato yield and income. The weights represent the importance of the different criteria to the farmer. Farmers need satisfaction and uncertainty tolerance level are randomly selected between 0 and 1 .

\begin{tabular}{lllllll}
\hline $\begin{array}{l}\text { Farmer } \\
\text { type }\end{array}$ & Description & $\begin{array}{l}\text { Need } \\
\text { satisfaction }\end{array}$ & $\begin{array}{l}\text { Uncertainty } \\
\text { tolerance } \\
\text { level }\end{array}$ & $\begin{array}{l}\text { Weight of } \\
\text { yield criterion } \\
\left(w_{\mathrm{p}}\right)\end{array}$ & $\begin{array}{l}\text { Weight of } \\
\text { income } \\
\text { criterion }\left(w_{\mathrm{y}}\right)\end{array}$ & $\begin{array}{l}\text { Weight of } \\
\text { infection level } \\
\text { criterion }\left(w_{\mathrm{d}}\right)\end{array}$ \\
\hline 1 & Yield maximizer & $0-1$ & $0-1$ & 0.8 & 0.1 & 0.1 \\
2 & Profit maximizer & $0-1$ & $0-1$ & 0.1 & 0.8 & 0.1 \\
3 & Risk averse farmer & $0-1$ & $0-1$ & 0.1 & 0.1 & 0.8 \\
4 & Neutral farmer & $0-1$ & $0-1$ & 0.33 & 0.33 & 0.33 \\
\hline
\end{tabular}

\subsubsection{Late blight management strategies in the model}

In the Netherlands the use of fungicides is currently the most widely used method in the control of late blight while crop resistance has been identified as an important strategy for more sustainable control (Haverkort et al., 2008; Lammerts Van Bueren et al., 2008). Combining these two types of disease control results in the following four strategies: growing a susceptible potato variety with (sus+) or without fungicide application (sus-), or growing a resistant potato variety with (res+) or without fungicide application (res-). In the model farmers select one of these strategies for their potato field (Figure 1). The management strategies can be related to current farm practices of conventional and organic farmers. In conventional agriculture, mainly susceptible varieties are grown combined with fungicide application (sus+). Since chemical control is not allowed in organic potato production and not enough resistant potatoes are available to supply the whole market (Bionext, 2017), organic farmers grow a combination of susceptible and resistant varieties and do not apply fungicides (sus- and res-). In years with early outbreaks of the disease, organic farmers can therefore suffer high yield losses in susceptible fields, but in years with a low infection pressure farmers can make a profit. Combining a resistant variety with (reduced use of) fungicides (res+) has been proposed to prevent resistance breakdown and to increase resistance durability (Haverkort et al., 2016). This strategy has also been described as part of integrated disease management to reduce the use of chemical fungicides (Kirk et al., 2005; Mundt et al., 2002; Nærstad et al., 2007). Although we 
do not distinguish organic and conventional potato production in the model, the late blight management strategies represent the different approaches in late blight control.

In case fungicides are used on susceptible and resistant fields (sus+ and res+), weekly application is assumed starting at the day of crop emergence. Weekly application is standard practice for many potato farmers, also because it is combined with the application of other chemicals for other diseases. Decision support systems (DSS) are available that can help farmers to improve efficiency of spraying by optimizing the use and timing of fungicide application. However, many farmers do not strictly follow their advice. Over the season farmers use different type of chemicals. In the model we distinguish preventive and curative fungicides. We assume preventive fungicides are applied at the start of the growing season to reduce the infection efficiency of the spores. When the disease severity in potato grid cells reaches $1 \%$, curative fungicides are applied which have a similar effect on the infection efficiency, but also reduce the expansion of existing lesions.

To prevent spread of the disease during the growing season the government has implemented a policy that regulates maximum late blight disease thresholds (NVWA, 2008). At an estimated disease severity of $5 \%$ in the field, the potato haulm has to be destroyed. An inspection system was set up, including an anonymous hotline, that could fine farmers in case these regulations were not followed. Following these regulations we assume that all farmers in the model destroy the potato haulm when the disease severity in potato grid cells reaches $5 \%$. This means that leaf and tuber growth stops directly and the disease can no longer disperse to other fields. In case of early outbreaks of the disease, this can cause severe yield losses.

Besides these strategies also other strategies exist that could be used in late blight control such as pre-sprouting (to reduce the growing period), soil management and chemicals against infections in tubers (Pacilly et al., 2016). However, some of these strategies only have a small effect while others are too complex to implement in the model. To allow integration with processes on decision-making we only focus on fungicide application and crop resistance in late blight control at this stage. As a result of advancements in potato breeding it is expected that new late blight resistant varieties will enter the market the coming years. Therefore it is very relevant to analyse the use of crop resistance in disease control.

\subsubsection{Analysing field performance}

In the model we implemented three criteria to evaluate the field performance of farmers: late blight infection level, potato yield and income. Infection level is an important criterion to evaluate the effectiveness of the selected management strategy and infection in a field can also reduce potato yield and farmer income. Furthermore, late blight management strategies include trade-offs between infection level, yield and income. The application of fungicides can reduce the risk of 
infection and prevent yield losses but causes additional costs. Growing a resistant variety can reduce the risk of infection, but has a negative effect on potato yield and income since we assume that the resistant variety has a lower potential yield compared to the susceptible variety. In addition, growing a resistant variety creates a risk on resistance breakdown by emergence of a new virulent strain. To evaluate the field performance in relation to late blight management strategies it is therefore important to consider all three criteria. Secondly, the importance of these criteria also differs between farmers (Table 1 ).

\section{Infection level}

In the model, late blight severity (percentage of infected leaf tissue) within a field is affected by the weather conditions, disease dispersal and late blight management strategies (fungicide use and crop resistance). The simulated disease severity ranged from no or very low disease severity to a very high disease severity $\left(10^{-4} \%\right.$ to $\left.>5 \%\right)$. Development of the disease at field level is limited since we assume that the potato haulm is destroyed when disease severity reaches $5 \%$. In practice in the field disease severity is generally estimated visually. Because the human eye can estimate low and high disease severity more precisely than mid-range levels, it is proposed to correct this by using a logarithmic rather than a linear scale (Cooke, 2006). Taken these factors into account a scale from 1 to 4 was developed to analyse the infection level using data on disease severity: $1:<0.1 \%, 2: 0.1-1 \%, 3: 1-5 \%$, 4: $>5 \%$.

\section{Potato yield}

At the end of the growing season the mean potato yield (tonnes/ha) of farmers is calculated. Potato yield is affected by the potato variety, weather conditions including temperature and radiation, and infection with late blight. In the model we assume that the resistant potato variety has a $20 \%$ lower potential yield compared to the susceptible variety.

\section{Income}

We use a standard approach to calculate farmer income: farmers' gross margin ( $\left.€ \mathrm{ha}^{-1}\right)$ is based on the actual potato yield times the price for potatoes minus production costs. With respect to production costs we only consider the costs related to fungicide application since we focus on comparing late blight management strategies. Costs for fungicides are related to the number of applications, the type of fungicides used, machinery, labour and fuel. The mean number of applications per farmer was calculated over the year (assuming weekly application) and the costs per application $\left(f_{c}\right)$ were estimated at $€ 50 \mathrm{ha}^{-1}$ (Haverkort et al., 2008). The price for potatoes was set on $€ 13$ per $100 \mathrm{~kg}$ which was derived from a dataset on potato prices for conventional ware potatoes in 
the Netherlands between 2000 and 2017 (WUR, 2018). The same price was used for the susceptible and resistant variety. Correlations between potato price and overall potato yield were not included because input and output markets are beyond the scope of this reginal study. Crop prices were assumed to be constant over time. In reality the crop price is affected by many other factors such as market fluctuations and the market farmers produce for (e.g. organic, conventional, frozen and fry, table and fresh) (Haverkort et al., 2008; Pavlista and Feuz, 2005). Furthermore to prevent price risks most farmers have contracts with trading companies on crop prices. Since we focus on comparing differences in income related to late blight management strategies these factors were not included in the current model version. As a result of this simplification values on income do not represent actual numbers.

\subsubsection{Farmer population}

Many studies have shown the importance of social interactions within networks in decision making processes, also with respect to Dutch farmers (Oerlemans and Assouline, 2004; Van Duinen et al., 2016). According to the Consumat approach agents are influenced through interactions within networks when they engage in social comparison or imitation. Unfortunately no empirical data was available on social networks among Dutch potato farmers, however, previous results from interviews showed that potato farmers influence each other and copy each other's behaviour (Pacilly et al., 2016). Since farmers have social interactions (e.g. as neighbours, friends and in study groups) and they spend much time on their land they are well aware how surrounding farmers manage their crops. Potato late blight disperses by wind so infections in neighbouring fields can increase the risk of infection. With respect to social interaction on late blight control we therefore assume farmers are in a network with the closest farmers around them (shortest distance between fields). In each model run, a network is initialised in which farmers are connected to the closest farmers around them (with a mean number of 5 links per farmer), representing a social network of neighbours. We explored the effect of alternative network structures (Appendix B). Increasing the mean number of links per farmer from 5 to 10 links did not affect the model results, as well as a different network setup in which farmers are connected to the closest farmers around them of the same type (assuming that you interact more with people who are more similar to you).

To create a heterogeneous population, characteristics of farmers are varied within a certain range. Farmers uncertainty tolerance level and need satisfaction are randomly selected between 0 and 1 . The weights represent the importance of the criteria to the farmer in their decision making. Based on these preferences farmers have different objectives resulting in four farmer types: yield maximizer, profit maximizer, risk averse farmer and neutral farmer. At the start of the simulation the farmer type of each farmer is randomly selected. Profit and yield maximizing farmers are types 
previously described in the literature (Malawska and Topping, 2016). Furthermore, studies have shown that farmers can have different risk attitudes which influences decision making on disease control (McRoberts et al., 2011; Willock et al., 1999). Gardebroek (2006) showed that Dutch farmers have different risk attitudes, which indicates that farmers manage risk differently. Organic farmers are less risk averse than conventional farmers but also within these groups risk attitudes were heterogeneous. Risk perception in late blight control can for example be related to the size of potential negative impact of infection on yield and income (Pacilly et al., 2016). Risk averse farmers would adopt strategies that reduce the risk of infection such as resistant varieties or fungicides, even when it comes at the expense of profit (Finger et al., 2017). Risk aversion can also result in the overuse of fungicides as was observed in the Netherlands (Skevas et al., 2012; Skevas et al., 2013). In the model the risk averse farmers therefore aim to minimize the infection level in their field. Last we distinguish a neutral farmer which does not have a preference for one of the criteria and the weights for the criteria are set equal (Table 1). For the other farmer types the weight of one of the criteria was set at 0.8 depending on their objective and for the other two criteria at 0.1 . The weights therefore represent clear differences in objectives between farmer types.

\subsubsection{Behavioural strategies}

According to the Consumat approach, behaviour of agents is affected by the levels of satisfaction and uncertainty. To determine farmers' satisfaction and uncertainty the actual $\left(\mathrm{a}_{\mathrm{i}}\right)$, potential $\left(\mathrm{p}_{\mathrm{i}}\right)$ and predicted $\left(e_{i}\right)$ performance is calculated for the three criteria: infection level, yield and income. The potential field performance is the maximum result which could be achieved in a specific year without any losses as a result of yield-limiting and yield-reducing factors (Van Ittersum and Rabbinge, 1997). In our model we only consider losses as a result of infection with the disease. The potential yield of both potato varieties is output of the model and based on the temperature and radiation in a specific year. The potential income is calculated in the same way as the actual income but using the potential yield. The potential infection level was set at 1 for all four strategies which represents the lowest level of disease severity that could be achieved.

Farmers also estimate the field performance for the coming year. For each performance criterion they calculate the mean value using historical values of their own field for the last five years. To create a list of reference values the model is run for five years before the actual simulation starts (see Appendix A). In the model, satisfaction is defined as the ratio between the actual and the potential performance, and uncertainty as the ratio between the actual and the estimated (predicted) performance. For each performance criterion the satisfaction and uncertainty is calculated. The overall satisfaction $\left(S_{t}\right)$ and uncertainty $\left(U_{t}\right)$ is based on the result for each criterion (i) influenced by the weights $\left(w_{i}\right)$ (Equations 1 and 2 ). 
$S_{t}=\sum w_{i} a_{i} / p_{i}$

$U_{t}=\sum w_{i} a_{i} / e_{i}$

Based on the Consumat approach farmers compare their total satisfaction and uncertainty level with their personal need satisfaction and uncertainly tolerance level. If the results are below their thresholds, farmers are uncertain and/or unsatisfied. Based on these results farmers engage in one of the following behavioural strategies (indicated below in italics). The Consumat approach is a highly formalized theory which describes very detailed how agents make decisions according to their behavioural strategy. The Consumat approach could be easily applied to farmers' decision-making on late blight management strategies. If a farmer is satisfied and certain he will repeat its current behaviour and continue using the same management strategy (repetition). If a farmer is uncertain he will interact with other farmers in his network to make an informed decision. Agents who are uncertain are more likely to engage in strategies that involve interactions, while agents who are certain are more likely to rely on their own experiences. If a farmer is uncertain but satisfied he will engage in imitation. In this case he will adopt the management strategy that is used by the majority of farmers in his network. When farmers are unsatisfied they engage in strategic decision making (optimisation or social comparison). This strategy relates to rational decision making in which farmers are aiming to optimize their field performance in relation to their preferences. First they select the criterion which they want to optimize: infection level, yield or income (See Section 2.1.3 and 2.1.4). This is based on the satisfaction level for each criterion, and on the criteria weights (Table 1). In case farmers are unsatisfied and uncertain, they engage in social comparison. In this strategy farmers analyse the field performance of the farmers in their network and adopt the management strategy of the farmer that has the highest score for the specific criteria. When farmers are unsatisfied but certain, they engage in optimising behaviour (optimisation). In this case they compare the mean field performance of all management strategies of the last year and adopt the management strategy that has the highest result for the criteria they want to improve. When the resistant variety with and without fungicides have the same score for a criterion it is assumed that farmers select the resistant variety without fungicides.

\subsection{Scenario analysis}

We assumed a situation where a new resistant potato variety was introduced to the market. We analysed the effect on disease control by adoption of the resistant variety by farmers and the durability of resistance. At the start of the simulation all farmers are growing a susceptible variety and the majority applies fungicides (90\%). Three scenarios were explored in which we analysed the 
effect of higher fungicide costs and higher yield or potato price of the resistant variety. These changes represent possible future scenarios as a result of actions by stakeholders.

First we increased the yield potential of the resistant potato variety so it is similar to the susceptible variety (yield-scenario). Breeding companies continue to develop new late blight resistant potato varieties and it is likely that in the future new resistant varieties will be introduced with higher yield levels. Secondly, as a result of stakeholder cooperation, the price for resistant varieties could increase in the future. In the standard settings the crop price of resistant and susceptible varieties was the same. Recently, the organic sector made an agreement to upscale the production of resistant varieties to completely service the organic market over the coming years (Bionext, 2017). An increase in demand could also result in a higher crop price. In the price-scenario we therefore increased the price of the resistant variety by $25 \%$.

In the third scenario (fungicide-scenario) we doubled the price per fungicide application (from $€ 50 \mathrm{ha}^{-1}$ to $€ 100 \mathrm{ha}^{-1}$ ). About half of all fungicides applied in the Netherlands are used in the control of late blight. The environmental costs are related to the pollution of groundwater, energy costs for application and negative effects on human health (Haverkort et al., 2008). Increased environmental awareness could possibly lead to higher prices for fungicides, for example, when government increases taxes. Economic instruments such as pesticide taxes can contribute to an optimal pesticide policy (Finger et al., 2017; Skevas et al., 2013). We analysed how these changes could affect the adoption of management strategies by farmers and the control of late blight.

To analyse the model results a number of output variables were calculated at the end of each growing season. We recorded the behavioural strategies and management strategies of farmers as well as the mean performance per strategy for the criteria infection level, yield and income. To analyse disease dynamics we calculated the disease incidence (the percentage of infected potato grid cells with a disease severity $\geq 1 \%$ ) (Skelsey et al., 2010) and the infected resistant fields (the percentage of resistant potato grid cells in the landscape infected with the virulent strain). We also recorded the year infections in resistant fields were observed followed by establishment of the virulent strain in the population (year of resistance breakdown). This occurs as a result of between year survival of the virulent strain resulting in initial infections in the following year. For each scenario, simulation runs were repeated 100 times.

\section{Results}

\subsection{Dynamics over time}




\subsubsection{Example of two model runs}

For the analysis of the results we observed the patterns that emerged from the model. Patterns are described as observations of any kind showing non-random structure and therefore containing information on the underlying mechanisms (Grimm et al., 2005). After 50 years of simulation we observed two different patterns. In the first pattern at some moment during the simulation infections in resistant fields were observed and the virulent strain established in the population (Figure 3e), while in the second pattern this process was not observed (Figure 3k). So in the first pattern resistance breakdown occurred while in the other pattern resistance remained effective during the simulation time. To analyse the dynamics over time an example of one model run of both patterns is shown in Figure 3.

From the start of the simulation in both patterns the number of susceptible fields decreased and the number of resistant fields increased (Figures 3a and 3g). Susceptible fields without fungicide application had a high risk of infection, and yield and income are fluctuating strongly as a result of the weather conditions that affect spread of the disease. Fungicide application on susceptible fields could not prevent infection completely but no large losses in yield and income were observed. Due to infection with late blight farmers were unsatisfied with their field performance which led to optimizing behaviour (Figures $3 \mathrm{f}$ and $3 \mathrm{I}$ ). Farmers that optimized on infection level adopted the resistant variety since this strategy scored better on infection level as a result of crop resistance (Figure 3b and 3h). In the model it was assumed that farmers won't apply additional fungicides on the resistant variety when the resistance is effective so farmers adopted the resistant variety without fungicides.

In both simulation runs after a couple of years a small percentage of resistant fields was infected by emergence of a virulent strain (Figures $3 e$ and $3 \mathrm{k}$ ). However, in pattern 2 the virulent strain was not able to spread and establish in the population. A small number of farmers responded to this event and switched to the resistant variety with fungicide application (Figure 3g).

In pattern 1 after 8 years the virulent strain was able to establish in the population and the percentage of infected resistant fields rapidly increased over time (Figures $3 e$ and 4). As a result of the relative high percentage of resistant fields $( \pm 20 \%)$ the virulent strain could spread fast through the landscape which gave farmers a very short time to adapt. When the percentage of infected resistant fields reached $55 \%$ the percentage of farmers growing a resistant variety without fungicides started to decrease. The spread of the virulent strain led to simulated losses in yield and income of resistant fields, which resulted in reduced farmer satisfaction and increased uncertainty, and farmers switching to other management strategies. Mean yield and income of resistant varieties without fungicide application decreased by $\pm 25 \%$ (Table 5). 


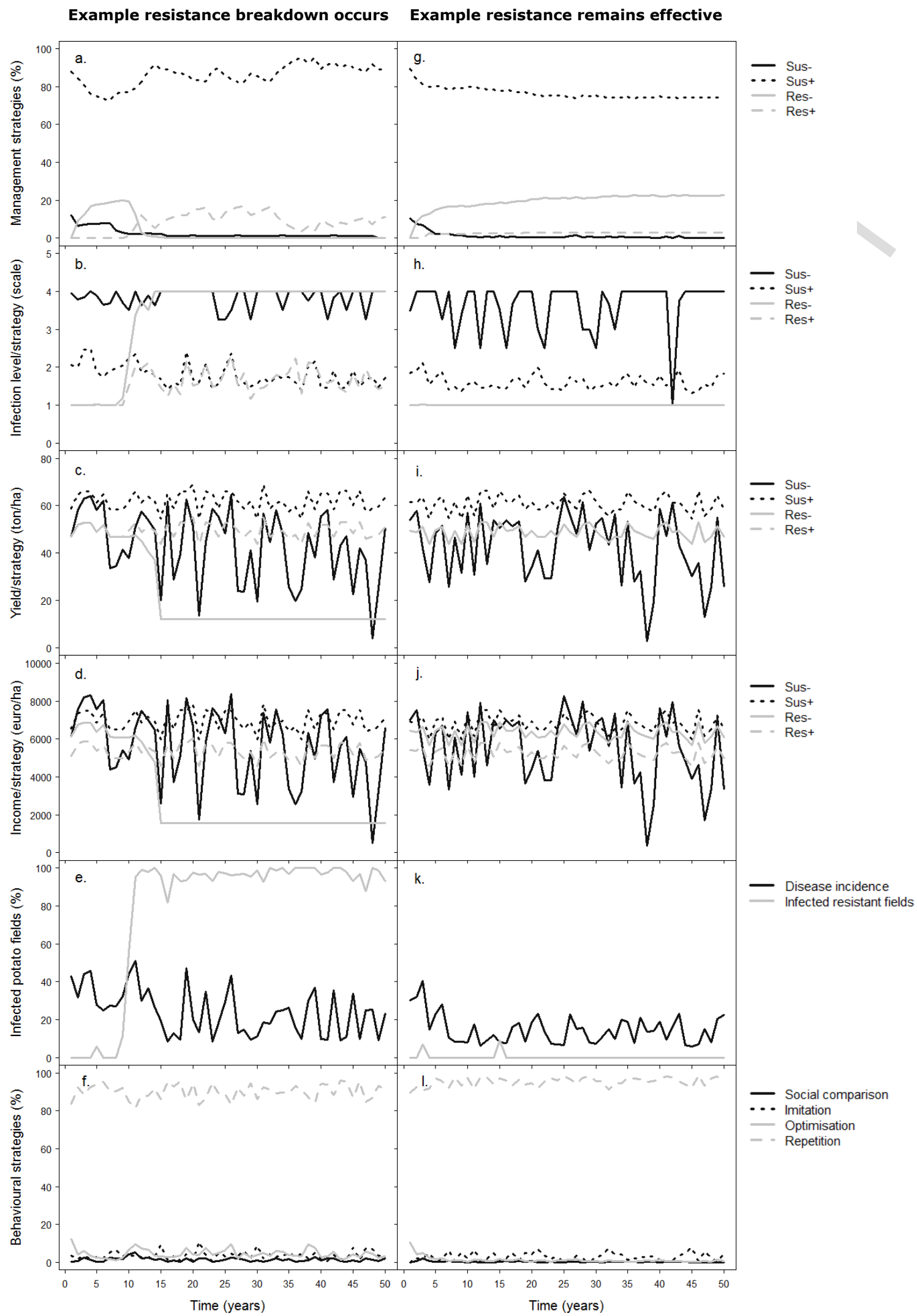

Figure 3. Example of two model runs with (a-f) or without (g-l) crop disease-resistance breakdown. In the figures we show the management strategies of farmers ( $a$ and $g$ ), the mean field performance per management strategy for the criteria infection level ( $b$ and $h$ ), yield ( $c$ and $i)$ and income ( $d$ and $j$ ), the spread of the disease in the landscape using the disease incidence and the infected resistant fields ( $e$ and $k$ ) and the behavioural strategies of farmers ( $\mathrm{f}$ and $\mathrm{I}$ ). 


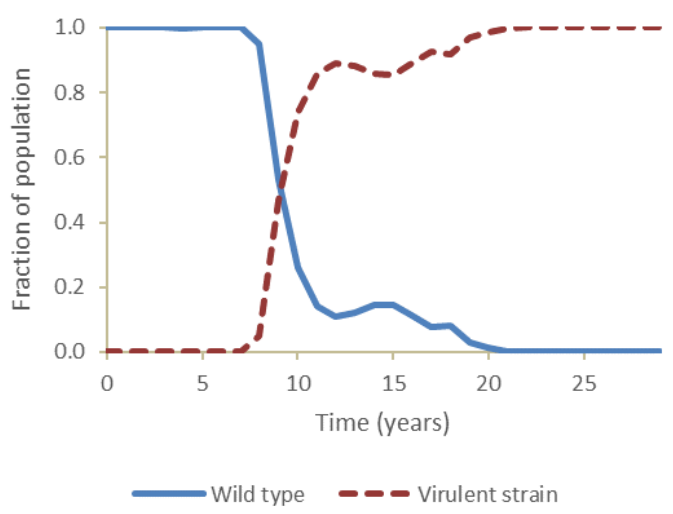

Figure 4. Population dynamics of late blight showing the emergence and spread of the virulent strain. The figure presents an example of one model run in which resistance breakdown occurred (see also Figure 3) and shows the proportion of disease severity caused by infection with the wild-type (solid line) and virulent strain (dashed line).

Social comparison and imitation mainly led to the adoption of the susceptible variety with fungicide application since this management strategy is used by the majority of the farmers and resulted in a lower infection level and higher yield and income. Optimising behaviour on infection level led to the adoption of the resistant variety with fungicide application. However, because the virulent strain was already present in the population, additional fungicide application only slowed down infection within the field, but could not eradicate the virulent strain from the landscape. As a result, the infection level in fields with the initially resistant variety increased, and yield and income of resistant fields without fungicides decreased. Since the resistant variety had a lower potential yield compared to the susceptible variety at some point the yield of resistant fields without fungicides dropped below the yield of susceptible fields without fungicide application. Within five years after the first resistant fields were infected almost no farmers were growing the resistant variety without fungicides anymore. The majority of farmers adopted the susceptible variety with fungicides and a small number of farmers the resistant variety with fungicides (Figure 3a). The resistant variety with fungicides had a lower level for yield and income but in some years had a lower infection level. After resistance breakdown the disease incidence in the landscape was highly variable per year. A small fraction of farmers remained unsatisfied and/or uncertain resulting in social comparing, optimising and imitating behaviour. However, no alternative strategies were available that led to a significant improvement.

In the simulation runs in the baseline scenario where resistance was still effective after 50 years, the percentage of farmers growing a resistant variety stabilized at $19.5 \% \pm 3.1$ (SD) (Table 2). This was also observed in the example shown in Figure $3 \mathrm{~b}$. The majority of farmers was growing the susceptible variety with fungicide application $(79.0 \% \pm 2.4)$. Most farmers were satisfied and certain 
about their field performance and engaged in repeating behaviour which resulted in a stable situation with respect to late blight management strategies.

After 50 years of simulation no strong spatial pattern in management strategies was observed. Clusters of farmers growing the resistant were observed as well as farmers growing a resistant variety surrounded by susceptible fields (Figure 2 ). This shows that besides spatial processes including disease spread and the social network also individual characteristics of farmers have a strong effect on decision-making. When resistance breakdown occurred the spatial distribution of management strategies seemed more random since the majority of farmers $( \pm 92 \%)$ is using the same strategy: susceptible variety with fungicides (Table 2).

Table 2. Management strategies of farmers (\%) at the end of the simulation (year 50) in case resistance breakdown occurs and in case the resistance remains effective. Mean values are shown ( \pm SD) based on 100 runs.

\begin{tabular}{lcccr}
\hline & \multicolumn{3}{c}{$\begin{array}{c}\text { Management strategies of farmers (\%) } \\
\text { Res- }\end{array}$} & Res+ \\
\hline Resistance breakdown occurs & Sus- & Sust & & \\
Baseline & & & & \\
Higher fungicide costs & $0.9 \pm 0.7$ & $92.0 \pm 3.7$ & $0.2 \pm 1.4$ & $6.9 \pm 3.5$ \\
Higher crop price resistant variety & $1.1 \pm 1.2$ & $92.1 \pm 4.2$ & $0.3 \pm 2.5$ & $6.4 \pm 3.7$ \\
Higher yield resistant variety & $0.8 \pm 0.5$ & $90.2 \pm 4.7$ & $0.8 \pm 4.3$ & $8.2 \pm 3.8$ \\
& $0.9 \pm 0.5$ & $88.1 \pm 4.8$ & $0.1 \pm 0.6$ & $10.9 \pm 4.7$ \\
Resistance remains effective & & & & \\
Baseline & & & & $1.0 \pm 1.9$ \\
Higher fungicide costs & $0.6 \pm 0.6$ & $79.0 \pm 2.4$ & $19.5 \pm 3.1$ & $0.2 \pm 0.6$ \\
Higher crop price resistant variety & $0.5 \pm 0.5$ & $74.2 \pm 3.2$ & $25.0 \pm 3.2$ & $0.3 \pm 0.9$ \\
Higher yield resistant variety & $0.5 \pm 0.4$ & $74.8 \pm 3.3$ & $24.5 \pm 3.4$ & $0.6 \pm 1.4$ \\
\hline
\end{tabular}

Table 3. Year of resistance breakdown as a result of establishment of the virulent strain in different scenarios. For each scenario the model was run 100 times.

\begin{tabular}{lrrrrrr}
\hline $\begin{array}{l}\text { Year resistance breakdown } \\
\text { (percentage of runs) }\end{array}$ & $\mathbf{0 - 1 0}$ & $\mathbf{1 0 - 2 0}$ & $\mathbf{2 0 - 3 0}$ & $\mathbf{3 0 - 4 0}$ & $\mathbf{4 0 - 5 0}$ & $>\mathbf{5 0}$ \\
\hline Baseline & 41 & 17 & 5 & 4 & 6 & $\mathbf{2 7}$ \\
Higher fungicide costs & 44 & 18 & 5 & 5 & 1 & 27 \\
Higher crop price resistant variety & 46 & 9 & 7 & 2 & 5 & 31 \\
Higher yield resistant variety & 44 & 11 & 4 & 5 & 1 & 35 \\
\hline
\end{tabular}

\subsubsection{Time until resistance breakdown}

The year of emergence of infections in resistant fields followed by establishment of the virulent strain in the population was analysed (Table 3). Resistance breakdown was observed in $73 \%$ of the model runs. In $42 \%$ of the model runs establishment of the virulent strain occurred in the first 10 years after the introduction of the resistant variety followed by an additional $17 \%$ during the ten following years. Once this period had passed the risk of establishment decreased. In $27 \%$ of the model runs the resistance was still effective after 50 years. The first years after introduction of the resistant variety a larger number of farmers was growing a susceptible variety without fungicide 
application. These fields could act as sources of infection and there was an increased risk that the virulent strain emerged. In the year the virulent strain established in the population the mean percentage of farmers that used a susceptible variety without fungicides was $2.0 \% \pm 1.5$. After this first period the risk of establishment decreased as a result of a lower fraction of susceptible fields without fungicides. However, as long as farmers are present that grow the susceptible fields without fungicides resistance breakdown can occur, which was also observed in the model after 30 or 40 years. In a sensitivity analysis we varied the initial fraction of farmers growing a susceptible variety without fungicides (Appendix $\mathrm{C}$ ). The results showed that increasing the initial fraction of farmers growing a susceptible variety without fungicides increased the risk on resistance breakdown and establishment of the virulent strain mainly during the first ten years of the simulation which shows that these fields act as an infection source of the virulent strain. However, no strong affect was observed on the management of farmers at the end of the simulation (Appendix C).

\subsubsection{Farmer characteristics}

We analysed the personal characteristics of farmers per management strategy at the end of the simulation (Table 4). The results show how farmer characteristics affect decision-making and the adoption of management strategies during the simulation. Farmers growing a susceptible variety without fungicides mainly had a low need satisfaction (0.35) and uncertainty tolerance level (0.31). As a result they mainly engaged in repeating behaviour and the farmers growing the susceptible variety without fungicides from the start of the simulation were less likely to change their strategy. Since this strategy resulted in most years in a higher infection level, lower yield level and lower income compared to the other strategies (Table 5), almost no farmers adopted this strategy during the simulation.

Farmers growing a resistant variety with or without fungicides had a relative high need satisfaction (0.72-0.75) and also a high value for the weight infection level (0.62), which shows that these were mainly risk averse farmers (Table 1). Unsatisfied farmers engaging in optimizing behaviour related to infection level would select the resistant variety without fungicide application and after infections in resistant fields, the resistant variety with fungicides. However, when both of these strategies were not effective anymore to prevent infection they switched back to the susceptible variety with fungicides.

Farmers growing the susceptible variety with fungicides were a large group of farmers. The weights for the criteria infection level, yield and income were almost equal and standard deviations were high, which indicates that these farmers were a mix of yield optimizers, income maximizers and neutral farmers. In the baseline scenario the susceptible variety with fungicide application resulted in the highest yield and income (Table 5). Growing the susceptible variety with fungicides did not result 
in losses in yield and income as a result of infection and therefore many farmers continued using this strategy.

Table 4. Characteristics of farmers per management strategy at the end of the simulation (year 50). Mean values are shown $( \pm S D)$ based on 100 model runs. At the start of the simulation farmers' uncertainty tolerance level and need satisfaction were randomly selected between 0 and 1 . The weights represent the importance of the criteria to the farmer in their decision making. The weights are dependent on the farmer type shown in Table 1.

\begin{tabular}{lccccc}
\hline $\begin{array}{l}\text { Management } \\
\text { strategy }\end{array}$ & $\begin{array}{c}\text { Need } \\
\text { satisfaction }\end{array}$ & $\begin{array}{c}\text { Uncertainty } \\
\text { tolerance } \\
\text { level }\end{array}$ & $\begin{array}{c}\text { Weight } \\
\text { infection } \\
\text { level }\end{array}$ & $\begin{array}{c}\text { Weight } \\
\text { yield }\end{array}$ & $\begin{array}{c}\text { Weight } \\
\text { income }\end{array}$ \\
\hline Sus- & $0.35 \pm 0.40$ & $0.31 \pm 0.24$ & $0.41 \pm 0.32$ & $0.21 \pm 0.21$ & $0.38 \pm 0.31$ \\
Sus+ & $0.48 \pm 0.28$ & $0.51 \pm 0.29$ & $0.30 \pm 0.27$ & $0.35 \pm 0.30$ & $0.35 \pm 0.29$ \\
Res- & $0.72 \pm 0.22$ & $0.50 \pm 0.28$ & $0.61 \pm 0.24$ & $0.19 \pm 0.13$ & $0.19 \pm 0.15$ \\
Res+ & $0.75 \pm 0.19$ & $0.40 \pm 0.26$ & $0.62 \pm 0.23$ & $0.19 \pm 0.12$ & $0.19 \pm 0.12$ \\
\hline
\end{tabular}

Table 5. Mean performance per management strategy for the criteria infection level, yield and income per scenario: $\mathrm{B}=$ Baseline, $\mathrm{F}=$ Higher fungicide costs, $\mathrm{P}=$ Higher potato price resistant variety, $\mathrm{Y}=$ Higher yield resistant variety. Mean values $( \pm S D)$ are shown based on 100 runs. Model results in the baseline scenario are highlighted in grey.

\begin{tabular}{|c|c|c|c|c|c|}
\hline & Scenario & Sus- & Sust & Res- & Rest \\
\hline \multicolumn{6}{|l|}{$\begin{array}{l}\text { Resistance } \\
\text { breakdown occurs }\end{array}$} \\
\hline \multirow[t]{4}{*}{ Infection level (-) } & B & $3.8 \pm 0.4$ & $1.8 \pm 0.3$ & $3.4 \pm 0.9$ & $1.7 \pm 0.4$ \\
\hline & $\mathrm{F}$ & $3.9 \pm 0.4$ & $1.8 \pm 0.3$ & $3.6 \pm 0.8$ & $1.8 \pm 0.4$ \\
\hline & $P$ & $3.9 \pm 0.3$ & $1.8 \pm 0.3$ & $3.6 \pm 0.7$ & $1.7 \pm 0.4$ \\
\hline & $\mathrm{Y}$ & $3.9 \pm 0.4$ & $1.8 \pm 0.3$ & $3.7 \pm 0.7$ & $1.7 \pm 0.5$ \\
\hline \multirow[t]{4}{*}{ Yield $\left(\mathrm{t} \mathrm{ha} \mathrm{h}^{-1}\right)$} & B & $42.2 \pm 15.3$ & $61.9 \pm 3.5$ & $37.7 \pm 11.9$ & $49.5 \pm 2.8$ \\
\hline & $\mathrm{F}$ & $41.9 \pm 15.5$ & $61.9 \pm 3.6$ & $36.4 \pm 13.1$ & $49.6 \pm 2.9$ \\
\hline & $P$ & $42.2 \pm 15.4$ & $62.0 \pm 3.5$ & $35.4 \pm 13.0$ & $49.5 \pm 2.9$ \\
\hline & $\mathrm{Y}$ & $42.5 \pm 15.4$ & $61.9 \pm 3.5$ & $44.3 \pm 15.8$ & $61.9 \pm 3.3$ \\
\hline \multirow[t]{4}{*}{ Income ( $€$ ha-1) } & B & $5488 \pm 1995$ & $6950 \pm 454$ & $4900 \pm 1546$ & $5335 \pm 362$ \\
\hline & $\mathrm{F}$ & $5445 \pm 2017$ & $5863 \pm 469$ & $4734 \pm 1700$ & $4265 \pm 382$ \\
\hline & $P$ & $5482 \pm 2003$ & $6963 \pm 460$ & $5761 \pm 2110$ & $6954 \pm 470$ \\
\hline & Y & $5524 \pm 1996$ & $6958 \pm 460$ & $5765 \pm 2060$ & $6949 \pm 430$ \\
\hline \multicolumn{6}{|l|}{$\begin{array}{l}\text { Resistance } \\
\text { remains effective }\end{array}$} \\
\hline \multirow[t]{4}{*}{ Infection level (-) } & B & $3.8 \pm 0.5$ & $1.8 \pm 0.3$ & $1.0 \pm 0.1$ & $1.0 \pm 0.0$ \\
\hline & & $3.7 \pm 0.5$ & $1.7 \pm 0.3$ & $1.0 \pm 0.1$ & $1.0 \pm 0.0$ \\
\hline & $P$ & $3.7 \pm 0.6$ & $1.7 \pm 0.3$ & $1.0 \pm 0.0$ & $1.0 \pm 0.0$ \\
\hline & & $3.7 \pm 0.6$ & $1.7 \pm 0.3$ & $1.0 \pm 0.0$ & $1.0 \pm 0.0$ \\
\hline \multirow[t]{4}{*}{ Yield (t ha-1) } & B & $43.3 \pm 14.9$ & $61.9 \pm 3.5$ & $49.6 \pm 2.8$ & $49.6 \pm 2.8$ \\
\hline & $\mathrm{F}$ & $43.8 \pm 14.6$ & $61.9 \pm 3.6$ & $49.6 \pm 2.9$ & $49.6 \pm 2.8$ \\
\hline & $P$ & $44.5 \pm 15.0$ & $62.1 \pm 3.5$ & $49.7 \pm 2.8$ & $49.7 \pm 2.7$ \\
\hline & $Y$ & $44.4 \pm 15.0$ & $61.9 \pm 3.5$ & $61.9 \pm 3.6$ & $62.1 \pm 3.5$ \\
\hline \multirow[t]{4}{*}{ Income (€ ha-1) } & B & $5623 \pm 1934$ & $6960 \pm 454$ & $6452 \pm 363$ & $5344 \pm 365$ \\
\hline & $\mathrm{F}$ & $5697 \pm 1898$ & $5862 \pm 473$ & $6446 \pm 377$ & $4249 \pm 369$ \\
\hline & $P$ & $5790 \pm 1952$ & $6980 \pm 458$ & $8071 \pm 460$ & $6980 \pm 446$ \\
\hline & $Y$ & $5775 \pm 1957$ & $6958 \pm 457$ & $8051 \pm 461$ & $6978 \pm 461$ \\
\hline
\end{tabular}




\subsection{Scenario analysis}

To compare the model scenarios, we analysed the management strategies of farmers after 50 years of simulation for the two patterns: with and without resistance breakdown (Table 2). Also the year resistance breakdown occurred was analysed as well as the mean field performance per management strategy (Tables 3 and 5). Overall we observed small effects of higher parameter values related to costs for fungicide application, yield level of the resistant variety and crop price of the resistant variety with respect to management strategies of farmers. In the situation where resistance breakdown occurred the percentage of farmers growing a resistant variety without fungicides remained low in all scenarios but the percentage of farmers growing a resistant variety with fungicides slightly increased in case of a higher crop price and higher yield level of the resistant variety (Table 2). When resistance was overcome by the pathogen the mean field performance of the resistant variety was lower or equal compared to the susceptible variety with fungicides in all scenarios (Table 5).

When resistance remained effective the percentage of farmers growing a resistant variety without fungicides increased from $19.5 \%$ to maximum $27.0 \%$. Increasing the yield level of the resistant variety had the largest effect since this resulted in a higher yield and income. In all three scenarios the resistant variety without fungicides resulted in a higher income compared to the susceptible variety with fungicides (Table 5). However, many farmers who started with the susceptible variety with fungicide application continued using this strategy because fungicides effectively suppress the disease so stable levels in yield and income are achieved. As a result, farmers were satisfied and certain and mainly engaged in repeating behaviour.

Differences in management strategies as a result of higher parameter values related to costs for fungicide application, yield level of the resistant variety and crop price of the resistant variety did not have a strong effect on resistance breakdown (Table 3). Some variation was observed mainly during the first 20 years of the simulation but this was probably the result of random processes such as the weather conditions and the allocation of potato fields since no large differences between management strategies were observed.

\section{Discussion}

\subsection{Boom-and-bust cycles}

Simulating the interactions between farmers' decision making and late blight dynamics increased understanding on the effects of adoption of a resistant potato variety by farmers on disease dynamics and resistance durability. Assuming a scenario where a new resistant variety with a single resistance gene became available, the model showed a gradual increase of farmers growing the 
resistant variety. In the majority of model runs resistance breakdown occurred within the first 20 years of the simulation by emergence of a new virulent strain. The virulent strain spread over the landscape and became dominant in the late blight population, decreasing yield and income of resistant fields. In the model, farmers responded to this event by switching to other management strategies, mainly to growing the susceptible variety with fungicide application.

This pattern has been described previously as a boom-and-bust cycle because of the often rapid rise and fall in the effectiveness of host resistance against pathogen populations in agriculture (Brown and Tellier, 2011; Pink and Puddephat, 1999). One cycle includes several stages: a) introduction of a resistant variety with a novel resistance gene source, b) increase in use of the resistant variety, c) emergence of a new virulent strain, d) a rapid increase of the virulent strain in the population, e) the complete loss of resistance in the crop, f) decrease in use of the variety with the specific resistance gene followed by g) decline of the virulent strain in the population (assuming fitness costs are associated to virulence). The cycle can be repeated multiple times when varieties are introduced with new resistance traits.

For potato late blight, boom-and-bust cycles have been observed after the introduction of resistant varieties from earlier breeding programs (Fry 2008). When varieties were introduced containing resistance genes from the closely related species Solanum demissum new virulent strains emerged that overcame resistance (Malcolmson, 1969). Boom-and-bust cycles are a general phenomenon in monocultures with gene-for-gene interactions and have also been described in other crops including oilseed rape, wheat and barley (De Vallavieille-Pope et al., 2012; Rouxel et al., 2003; Wolfe and McDermott, 1994).

In our model we assumed that no costs are associated with virulence hence the virulent strain did not decline in the population when farmers stopped growing the variety with the matching resistance gene. According to experimental data no or only few relations between fitness costs and virulence have been found (Montarry et al., 2010; Schöber and Turkensteen, 1992). In other crops it has been observed that virulent strains rarely revert to their initial frequencies after removal of the variety with the corresponding resistance gene (Mundt, 2014). This is relevant information with respect to deployment strategies such as gene rotation or stacked resistance with previously defeated resistance genes. If virulent strains remain present in the pathogen population these resistance management strategies will be less effective because the virulent strains can rapidly reproduce after reintroduction of resistance genes, or more easily adapt to varieties with multiple resistance genes when one of these genes has already been overcome.

A number of theoretical models exist that reproduced boom-and-bust cycles by simulating host-pathogen interactions at the landscape scale (Brown and Tellier, 2011), but as far as we know none of these included the interactions with respect to farmers' decision-making. By exploring the 
interactions between farmer behaviour and the spatially explicit evolutionary dynamics of the pathogen we identified potential factors and processes that could affect the adoption of a resistant potato variety and resistance durability. These factors and the implications for disease management are described in the following sections.

\subsection{Scenario analysis}

The results from this study showed that in the current situation the use of susceptible varieties with fungicide application resulted in the highest yield and income which is in line with current management strategies of conventional farmers. In all model scenarios almost no farmers were growing the susceptible variety without fungicides since this strategy resulted in most years in a high infection level and losses in yield and income. The organic sector currently represents about $1 \%$ of the total potato production area in the Netherlands. Due to severe late blight outbreaks between 2000 and 2007 and a lack of resistant varieties its acreage decreased by $20 \%$, showing that growing susceptible varieties without any effective control is not profitable in years with high disease pressure, even with a premium price for organic potatoes (Lammerts Van Bueren et al., 2008).

The scenarios including higher fungicide costs and higher yield or potato price of the resistant variety affected the field performance of management strategies, and consequently the selection of management strategies by farmers (Tables 2 and 5). When the resistance remained effective all three scenarios resulted in a higher yield and income of resistant fields without fungicides compared to susceptible fields with fungicides. As a result, more farmers adopted the resistant variety in the model and therefore these strategies could contribute to sustainable disease control. However, the risk on resistance breakdown was high and when the resistance was overcome farmers switched back to the use of fungicides. Farmers in the model were simulated as social agents who interacted with each other and the environment. Simulating the social-ecological interactions can increase insight in the potential effects of certain policies or changes in the socio-economic environment and be used to identify strategies that foster a transition towards more sustainable disease management.

\subsection{Regime shifts}

The model showed that resistance breakdown did not occur in all simulation runs. Emergence of virulent spores as a result of mutation has a low probability. In addition, spread of the virulent strain is affected by processes such as the weather conditions and allocation of potato varieties which varies between years and model runs. Resistance breakdown as a result of emergence and spread of the virulent strain in the late blight population could be described as a regime shift (Filatova et al., 2016). A regime shift transforms the system resulting in new properties, structure, feedbacks, and 
underlying behaviour of components or agents. When resistance breakdown occurred in the model the system changed with respect to the field performance of management strategies, farmer behaviour and the pathogen population (Figures 3 and 4). Regime shifts can occur as a result of gradual changes in the system components or from interactions between processes operating at different spatial and temporal scales. In the model establishment of the virulent strain occurred when the ratio between the wild type and virulent strain exceeded a threshold resulting in initial infections of the virulent strain in the following year. This threshold can be reached when the virulent strain is able to emerge and spread during the growing season which is affected by the management strategies of farmers as well as a number of random processes such as the weather conditions, the allocation of farmers and potato fields and the location of infection sources at the start of the growing season.

Predicting critical transitions is often very difficult because the state of the system may show little change before the tipping point is reached (Scheffer et al., 2009). With respect to late blight control it has been suggested to set up monitoring programmes to yield direct insight in the $P$. infestans adaptation process at population level (Haverkort et al., 2016; Kessel et al., 2018). When a virulent strain is detected and the resistance is at risk of being overcome, additional management strategies are needed, for example by additional application of fungicides on resistant fields. In the model farmers growing a resistant variety started applying additional fungicides but after infections in resistant fields were observed. At this point the application of fungicides could only slow down spread of the virulent strain but the resistance was already overcome. Monitoring programmes could therefore be very useful to inform farmers about the risk on infections in resistant fields so additional measures are taken before the virulent strain will spread in the population.

\subsection{Implications for late blight control}

The model showed that the risk on emergence of new virulent strains and resulting infections in resistant fields was mainly high during the first 10 years after the introduction of resistant variety. During this period the number of farmers growing the resistant variety gradually increased and farmers growing the susceptible variety without fungicides decreased. In this transition period there is a higher risk that virulent spores emerge from susceptible fields and spread to neighbouring resistant fields. This is relevant information since stakeholders in the Dutch organic potato sector recently agreed to upscale the use of late blight resistant varieties (Bionext, 2017). There is currently insufficient supply of resistant seed potatoes for the entire organic market so the coming years a situation will occur were organic farmers will grow partly susceptible and partly resistant varieties. During this transition phase organic farmers must be aware of the risk of resistance breakdown and take immediate countermeasures when they observe infections in resistant fields. The model 
showed that in some years a small fraction of resistant fields was infected but the virulent strain was not able to establish in the population. Therefore a strategy that could be used by farmers to increase resistance durability includes immediate haulm destruction to prevent spread and establishment of the virulent strain in the late blight population.

The results showed that when resistance remained effective only part of the farmer agents in the model adopted the resistant variety, even when this resulted in a higher yield and income compared to the susceptible variety. We started with a situation in which the majority of farmers was growing the susceptible variety with fungicides. The model showed that the effect of habitual behaviour is very strong which means that when farmer agents are satisfied and certain, they would not change their management strategy. Although fungicides could not prevent infection completely, they suppressed the disease so stable levels in yield and income are reached which resulted in a high satisfaction and low uncertainty of farmers. As a result, only risk averse farmers with a high need satisfaction adopted the resistant variety in the model. These results suggest that when new resistant varieties are introduced to the market investments are probably needed to promote these to farmers and to increase their adoption. Interviews with conventional farmers showed that they do not consider late blight as a big problem because the application of fungicides leads to effective and cheap control (Pacilly et al., 2016). These results support this finding. Secondly, to prevent emergence and spread of virulent strains additional management strategies are needed to increase durability of resistance. The development of sustainable crop protection systems therefore requires cooperation between actors in the whole sector to achieve structural transformations in disease control.

\subsection{Further research}

To simulate farmers' decision making we used the Consumat approach, a well-founded theory on human behaviour and previously used to simulate farmers' decision making. The implementation of the framework was supported by data from the literature on farmer behaviour and results from interviews with Dutch potato farmers. The model was able to reproduce patterns and trends observed in reality (e.g. boom-and-bust cycles) which supports the validity of the model framework (Grimm et al., 2005). However, different model structures at the micro-scale can lead to the same emergent patterns at the macro-scale (Schulze et al., 2017). Methods to validate processes on human behaviour include expert validation and role playing games (Ligtenberg et al., 2010). Secondly, alternative models of decision-making could be implemented to analyse the sensitivity of the results to different assumption of human decision making (Schlüter et al., 2017). These methods are important steps for further research. 
Besides implementing alternative theories on human behaviour we identified some other relevant processes that could be implemented for further research. We made simplifications on model components such as management strategies, the farmer population, the network structure and market effects. Although the model framework proved to be sufficient considering the purpose of this study, these processes could be extended in future research. Additional data collection could contribute to the implementation of these processes, for example collecting survey data of the farmer population. Secondly, in the current model the landscape consisted of farmers that each manage one potato field while in reality farmers can have multiple fields spread over the farm. These potato fields can be managed in different ways and farmers usually grow a number of different potato varieties, also as a way of risk management. The current model structure represents decisionmaking at field level. However, this result in a relatively high number of farmers in the model landscape. Thirdly, in the model we included only one susceptible and one resistant variety. Currently, a number of different resistant varieties is available with resistance genes from different sources. More diversity in crop resistance can potentially reduce the risk on resistance breakdown and spread of virulent strains (Lof and van der Werf, 2017; Mundt, 2014). Lastly, since potatoes are reproduced vegetatively by the use of seed potatoes it takes some time to increase the production of newly introduced potato varieties. The availability of seed potatoes can therefore constrain a rapid adoption of new resistant varieties. It would be interesting to implement these factors in the model to analyse the effect on the adoption of resistant varieties, the allocation of susceptible and resistant fields in the landscape and resistance durability.

In the model stakeholders such as breeding companies, the government and the market were represented as drivers of the system which influenced farmers' decision making. However, each of these stakeholders have their own objectives and interests which leads to various types of interactions such as competition, cooperation and trading (Pacilly et al., 2016). Agent-based models are very suitable to include multiple types of agents and their interactions. As a next step, it would be interesting to explore the interactions between farmers, other stakeholders and late blight dynamics. With respect to the use of crop resistance in late blight control it would be mainly interesting to focus on the role of breeding companies and the effect of breeding and marketing strategies on late blight control.

\section{Conclusion}

In this paper we combined a framework on farmer behaviour to an epidemiological framework on potato late blight to explore the use of crop resistance in disease control. The framework on farmers' decision making was based on the Consumat approach and supported by data from literature on farmer behaviour and interviews with Dutch potato farmers. After introduction of a new resistant 
variety the model reproduced a so-called boom-and-bust cycle: the percentage of farmers growing the resistant variety increased (boom) until resistance breakdown occurred by emergence and spread of a virulent strain, and in response farmers switched to other potato varieties and management strategies (bust). By exploring the interactions between farmer behaviour and late blight dynamics the model increased insights in the factors and processes that could affect the adoption of a resistant potato variety and resistance durability. For example, a higher crop price and yield of the resistant variety increased the adoption by farmers. However, also a large number of farmers continued growing the susceptible variety with fungicides which suggests that cooperation in the whole potato sector is needed to achieve structural transformations in disease control. In addition, the high risk on resistance breakdown stresses the importance of resistance management strategies to increase resistance durability. It was found that emergence and spread of the virulent strain is the result of interactions between management strategies of farmers, the weather conditions and the allocation of potato varieties.

By exploring the social-ecological interactions related to disease control the model contributed to the field of social-ecological system research and agent-based modelling. The number of models that tackles two-way feedbacks between social and ecological systems is scarce, also due to the inherent complexity of such systems (Filatova et al., 2013; Parker et al., 2008; Schulze et al., 2017). This study provides a framework for linking decision-making processes of farmers to disease dynamics in an agent-based model. Implementing these two-way linkages allowed us to explore nonlinear dynamics and feedback mechanisms within the social-ecological system. This approach could be useful for a whole range of systems focusing on management of emerging infectious diseases of crops.

\section{Acknowledgements}

We would like to thank the strategic research programme 'Complex Adaptive Systems' (IP/OP CAS) of Wageningen University \& Research for financing this research. The contribution of JG was partly funded by the CGIAR Research Program on Roots, Tubers and Bananas (RTB) and supported by CGIAR Fund Donors.

\section{References}

An, L., 2012. Modeling human decisions in coupled human and natural systems: Review of agent-based models. Ecological Modelling 229, 25-36.

Anderson, P.K., Cunningham, A.A., Patel, N.G., Morales, F.J., Epstein, P.R., Daszak, P., 2004. Emerging infectious diseases of plants: pathogen pollution, climate change and agrotechnology drivers. Trends in Ecology \& Evolution 19, 535-544. 
Austin, E.J., Willock, J., Deary, I.J., Gibson, G.J., Dent, J.B., Edwards-Jones, G., Morgan, O., Grieve, R., Sutherland, A., 1998. Empirical models of farmer behaviour using psychological, social and economic variables. Part I: linear modelling. Agricultural Systems 58, 203-224.

Bionext, 2017. 25 ketenpartijen ondertekenen convenant voor meer ziekteresistente biologische aardappelrassen, https://bionext.nl.

Brown, J.K.M., Tellier, A., 2011. Plant-parasite coevolution: Bridging the gap between genetics and ecology, Annual Review of Phytopathology, pp. 345-367.

Cooke, B.M., 2006. The Epidemiology of Plant Diseases. Springer Netherlands: Dordrecht, Dordrecht.

De Vallavieille-Pope, C., Ali, S., Leconte, M., Enjalbert, J., Delos, M., Rouzet, J., 2012. Virulence dynamics and regional structuring of Puccinia striiformis f. sp. tritici in France between 1984 and 2009. Plant Disease 96, 131-140.

Edwards-Jones, G., 2006. Modelling farmer decision-making: concepts, progress and challenges. Animal Science 82, 783-790.

Filatova, T., Polhill, J.G., van Ewijk, S., 2016. Regime shifts in coupled socio-environmental systems: Review of modelling challenges and approaches. Environmental Modelling and Software 75, 333-347.

Filatova, T., Verburg, P.H., Parker, D.C., Stannard, C.A., 2013. Spatial agent-based models for socioecological systems: Challenges and prospects. Environmental Modelling and Software 45, 1-7.

Finger, R., Möhring, N., Dalhaus, T., Böcker, T., 2017. Revisiting pesticide taxation schemes. Ecological Economics, 134, 263-266.

Gardebroek, C., 2006. Comparing risk attitudes of organic and non-organic farmers with a Bayesian random coefficient model. European Review of Agricultural Economics, 33(4), 485-510.

Gilbert, N., 2008. Agent-based models. Sage, Los Angeles, CA.

Grimm, V., Berger, U., Bastiansen, F., Eliassen, S., Ginot, V., Giske, J., Goss-Custard, J., Grand, T., Heinz, S.K., Huse, G., Huth, A., Jepsen, J.U., Jørgensen, C., Mooij, W.M., Müller, B., Pe'er, G., Piou, C., Railsback, S.F., Robbins, A.M., Robbins, M.M., Rossmanith, E., Rüger, N., Strand, E., Souissi, S., Stillman, R.A., Vabø, R., Visser, U., DeAngelis, D.L., 2006. A standard protocol for describing individualbased and agent-based models. Ecological Modelling 198, 115-126.

Grimm, V., Berger, U., DeAngelis, D.L., Polhill, J.G., Giske, J., Railsback, S.F., 2010. The ODD protocol: A review and first update. Ecological Modelling 221, 2760-2768.

Grimm, V., Revilla, E., Berger, U., Jeltsch, F., Mooij, W.M., Railsback, S.F., Thulke, H.H., Weiner, J., Wiegand, T., DeAngelis, D.L., 2005. Pattern-oriented modeling of agent-based complex systems: Lessons from ecology. Science 310, 987-991.

Groeneveld, J., Müller, B., Buchmann, C.M., Dressler, G., Guo, C., Hase, N., Hoffmann, F., John, F., Klassert, C., Lauf, T., Liebelt, V., Nolzen, H., Pannicke, N., Schulze, J., Weise, H., Schwarz, N., 2017. Theoretical foundations of human decision-making in agent-based land use models - A review. Environmental Modelling and Software 87, 39-48.

Haverkort, A.J., Boonekamp, P.M., Hutten, R., Jacobsen, E., Lotz, L.A.P., Kessel, G.J.T., Visser, R.G.F., Van Der Vossen, E.A.G., 2008. Societal costs of late blight in potato and prospects of durable resistance through cisgenic modification. Potato Research 51, 47-57.

Haverkort, A.J., Boonekamp, P.M., Hutten, R., Jacobsen, E., Lotz, L.A.P., Kessel, G.J.T., Vossen, J.H., Visser, R.G.F., 2016. Durable Late Blight Resistance in Potato Through Dynamic Varieties Obtained by Cisgenesis: Scientific and Societal Advances in the DuRPh Project. Potato Research, 1-32.

Huber, R., Bakker, M., Balmann, A., Berger, T., Bithell, M., Brown, C., Grêt-Regamey, A., Xiong, H., Bao Le, Q., Mack, M., Meyfroidt, P., Millington, J., Müller, B., Polhill, J.G., Sun, Z., Seidl, R., Troost, C., 
Finger, R., 2018. Representation of decision-making in European agricultural agent-based models. Agricultural Systems, 167, 143-160.

Jager, W., Janssen, M., 2012. An updated conceptual framework for integrated modeling of human decision making: The Consumat II, paper for workshop complexity in the Real World@ ECCS, pp. 1-18.

Jager, W., Janssen, M.A., De Vries, H.J.M., De Greef, J., Vlek, C.A.J., 2000. Behaviour in commons dilemmas: Homo economicus and Homo psychologicus in an ecological-economic model. Ecological Economics 35, 357-379.

Janssen, M.A., Jager, W., 2001. Fashions, habits and changing preferences: Simulation of psychological factors affecting market dynamics. Journal of Economic Psychology 22, 745-772.

Kessel, G.J.T., Mullins, E., Evenhuis, A., Stellingwerf, J., Cortes, V.O., Phelan, S., van den Bosch, T., Förch, M.G., Goedhart, P., van der Voet, H., Lotz, L.A.P., 2018. Development and validation of IPM strategies for the cultivation of cisgenically modified late blight resistant potato. European Journal of Agronomy 96, 146-155.

Kirk, W.W., Abu-El Samen, F.M., Muhinyuza, J.B., Hammerschmidt, R., Douches, D.S., Thill, C.A., Groza, H., Thompson, A.L., 2005. Evaluation of potato late blight management utilizing host plant resistance and reduced rates and frequencies of fungicide applications. Crop Protection 24 (11), 961-970.

Lammerts Van Bueren, E.T., Tiemens-Hulscher, M., Struik, P.C., 2008. Cisgenesis does not solve the late blight problem of organic potato production: Alternative breeding strategies. Potato Research 51, 89-99.

Ligtenberg, A., van Lammeren, R.J.A., Bregt, A.K., Beulens, A.J.M., 2010. Validation of an agent-based model for spatial planning: A role-playing approach. Computers, Environment and Urban Systems 34, 424-434.

Lof, M.E., van der Werf, W., 2017. Modelling the effect of gene deployment strategies on durability of plant resistance under selection. Crop Protection 97, 10-17.

Mack, R.N., Simberloff, D., Lonsdale, W.M., Evans, H., Clout, M., Bazzaz, F.A., 2000. Biotic invasions: Causes, epidemiology, global consequences, and control. Ecological Applications 10, 689-710.

Malawska, A., Topping, C.J., 2016. Evaluating the role of behavioral factors and practical constraints in the performance of an agent-based model of farmer decision making. Agricultural Systems 143, 136146.

Malcolmson, J.F., 1969. Races of Phytophthora infestans occurring in Great Britain. Transactions of the British Mycological Society 53, 417-IN412.

Matthews, R.B., Gilbert, N.G., Roach, A., Polhill, J.G., Gotts, N.M., 2007. Agent-based land-use models: A review of applications. Landscape Ecology 22, 1447-1459.

McRoberts, N., Hall, C., Madden, L.V., Hughes, G., 2011. Perceptions of Disease Risk: From Social Construction of Subjective Judgments to Rational Decision Making. Phytopathology 101, 654-665.

Montarry, J., Hamelin, F.M., Glais, I., Corbi, R., Andrivon, D., 2010. Fitness costs associated with unnecessary virulence factors and life history traits: Evolutionary insights from the potato late blight pathogen Phytophthora infestans. BMC Evolutionary Biology 10.

Mundt, C.C., 2014. Durable resistance: A key to sustainable management of pathogens and pests. Infection, Genetics and Evolution 27, 446-455.

Mundt, C.C., Cowger, C., Garrett, K.A., 2002. Relevance of integrated disease management to resistance durability. Euphytica 124, 245-252.

Nærstad, R., Hermansen, A., Bjor, T., 2007. Exploiting host resistance to reduce the use of fungicides to control potato late blight. Plant Pathology 56, 156-166. 
NVWA, 2008. Teeltvoorschriften Phytophthora infestans (cultivation requirements for phytophthora infestans management). Ministry of Economic Affairs.

Oerlemans, N., Assouline, G., 2004. Enhancing farmers' networking strategies for sustainable development. Journal of Cleaner Production 12, 468-477.

Pacilly, F.C.A., Groot, J.C.J., Hofstede, G.J., Schaap, B.F., van Bueren, E.T.L., 2016. Analysing potato late blight control as a social-ecological system using fuzzy cognitive mapping. Agronomy for Sustainable Development 36 (2), 1-18.

Pacilly, F.C.A., Hofstede, G.J., Lammerts van Bueren, E.T., Kessel, G.J.T., Groot, J.C.J., 2018. Simulating crop-disease interactions in agricultural landscapes to analyse the effectiveness of host resistance in disease control: The case of potato late blight. Ecological Modelling 378, 1-12.

Pacilly, F.C.A., Lammerts van Bueren, E.T., Groot, J.C.J., Hofstede, G.J., 2019. Moving perceptions on potato late blight control: workshops with model-based scenarios. Crop Protection 119, 76-87.

Parker, D.C., Hessl, A., Davis, S.C., 2008. Complexity, land-use modeling, and the human dimension: Fundamental challenges for mapping unknown outcome spaces. Geoforum 39, 789-804.

Parker, D.C., Manson, S.M., Janssen, M.A., Hoffmann, M.J., Deadman, P., 2003. Multi-agent systems for the simulation of land-use and land-cover change: A review. Annals of the Association of American Geographers 93, 314-337.

Pavlista, A.D., Feuz, D.M., 2005. Potato prices as affected by demand and yearly production. American Journal of Potato Research 82, 339-343.

Pink, D., Puddephat, L., 1999. Deployment of disease resistance genes by plant transformation - A 'mix and match' approach. Trends in Plant Science 4, 71-75.

Reidsma, P., Janssen, S., Jansen, J., Van Ittersum, M.K., 2018. On the development and use of farm models for policy impact assessment in the European Union-A review. Agricultural Systems 159, 111125.

Rouxel, T., Penaud, A., Pinochet, X., Brun, H., Gout, L., Delourme, R., Schmit, J., Balesdent, M.H., 2003 A 10-year survey of populations of Leptosphaeria maculans in France indicates a rapid adaptation towards the RIm1 resistance gene of oilseed rape. European Journal of Plant Pathology 109, 871-881.

Scheffer, M., Bascompte, J., Brock, W.A., Brovkin, V., Carpenter, S.R., Dakos, V., Held, H., Van Nes, E.H., Rietkerk, M., Sugihara, G., 2009. Early-warning signals for critical transitions. Nature 461, 53-59.

Schlüter, M., Baeza, A., Dressler, G., Frank, K., Groeneveld, J., Jager, W., Janssen, M.A., McAllister, R.R.J., Müller, B., Orach, K., Schwarz, N., Wijermans, N., 2017. A framework for mapping and comparing behavioural theories in models of social-ecological systems. Ecological Economics 131, 21-35.

Schlüter, M., McAllister, R.R.J., Arlinghaus, R., Bunnefeld, N., Eisenack, K., Hölker, F., Milner-Gulland, E.J., Müller, B., Nicholson, E., Quaas, M., Stöven, M., 2012. New horizons for managing the environment: A review of coupled social-ecological systems modeling. Natural Resource Modeling 25, 219-272.

Schöber, B., Turkensteen, L.J., 1992. Recent and future developments in potato fungal pathology. Netherlands Journal of Plant Pathology 98, 73-83.

Schulze, J., Müller, B., Groeneveld, J., Grimm, V., 2017. Agent-Based Modelling of Social-Ecological Systems: Achievements, Challenges, and a Way Forward. Journal of Artificial Societies and Social Simulation 20, 8.

Skelsey, P., Kessel, G.J.T., Rossing, W.A.H., Van Der Werf, W., 2009. Parameterization and evaluation of a spatiotemporal model of the potato late blight pathosystem. Phytopathology 99, 290-300. 
Skelsey, P., Rossing, W.A.H., Kessel, G.J.T., Van Der Werf, W., 2010. Invasion of Phytophthora infestans at the landscape level: How do spatial scale and weather modulate the consequences of spatial heterogeneity in host resistance? Phytopathology 100, 1146-1161.

Skevas, T., Stefanou, S.E., Lansink, A.O., 2012. Can economic incentives encourage actual reductions in pesticide use and environmental spillovers?. Agricultural Economics 43(3), 267-276.

Skevas, T., Lansink, A. O., Stefanou, S. E., 2013. Designing the emerging EU pesticide policy: A literature review. NJAS-Wageningen Journal of Life Sciences 64, 95-103.

Speelman, E.N., 2014. Gaming and simulation to explore resilience of contested agricultural landscapes. Wageningen University, Wageningen.

Van Duinen, R., Filatova, T., Jager, W., van der Veen, A., 2016. Going beyond perfect rationality: drought risk, economic choices and the influence of social networks. Annals of Regional Science 57, 335369.

Van Ittersum, M.K., Rabbinge, R., 1997. Concepts in production ecology for analysis and quantification of agricultural input-output combinations. Field Crops Research 52, 197-208.

Vurro, M., Bonciani, B., Vannacci, G., 2010. Emerging infectious diseases of crop plants in developing countries: Impact on agriculture and socio-economic consequences. Food Security 2, 113-132.

Wilensky, U., 1999. NetLogo. Center for Connected Learning and Computer-Based Modeling, Northwestern University, Evanston, IL., http://ccl.northwestern.edu/netlogo/.

Willock, J., Deary, I.J., McGregor, M.M., Sutherland, A., Edwards-Jones, G., Morgan, O., Dent, B., Grieve, R., Gibson, G., Austin, E., 1999. Farmers' attitudes, objectives, behaviors, and personality traits: The Edinburgh study of decision making on farms. Journal of Vocational Behavior 54, 5-36.

Wolfe, M.S., McDermott, J.M., 1994. Population genetics of plant pathogen interactions: The example of the Erysiphe graminis-Hordeum vulgare pathosystem. Annual Review of Phytopathology 32, 89-113.

WUR, 2018. Prijsontwikkeling consumptieaardappelen en uien, http://www.agrimatie.nl. 


\section{Appendix A Model description}

The model description follows the ODD (Overview, Design concepts, Details) protocol for describing agent-based models (Grimm et al., 2006; Grimm et al., 2010). In the model description we focus on the processes related to farmers' decision-making. For more details on the epidemiological framework, we refer to Pacilly et al. (2018).

\section{A.1 Model purpose}

The aim of the model is to simulate the interactions between farmers' decision making and late blight dynamics in an agricultural landscape with potato fields. The model is used to simulate the use of crop resistance in disease control by analysing the adoption of the resistant variety by farmers and the durability of resistance over time.

Table A.1. Overview of late blight management strategies implemented in the model.

\begin{tabular}{|l|ll|}
\hline & \multicolumn{2}{|l|}{ Fungicide application } \\
Potato variety & No & Yes \\
\hline Susceptible & Sus.- & Sus.+ \\
Resistant & Res.- & Res.+ \\
\hline
\end{tabular}

\begin{tabular}{l|l} 
Repetition & \multicolumn{1}{|l}{$\begin{array}{l}\text { Satisfaction } \\
+\end{array}$} \\
\hline Optimisation & $\begin{array}{l}\text { Uncertainty } \\
\text { Social } \\
\text { comparison }\end{array}$ \\
\hline-
\end{tabular}

Figure A.1. Overview of behavioural strategies in relation to farmers satisfaction and uncertainty according to the Consumat approach.

\section{A.2 Entities, state variables and scales}

The model includes three types of entities: farmers, grid cells and agricultural fields. The model represents an agricultural landscape of $10 \times 10 \mathrm{~km}^{2}$ and the grid cells are $200 \times 200 \mathrm{~m}^{2}$ (4 ha). The model is populated by farmers each of whom manages one potato field which consists of one or more grid cells. A network was initialised in which farmers are connected to the closest farmers around them (shortest distance) which represents a network of neighbours. An overview of farmer 
variables is shown in Table A.2. For the state variables and model parameters related grid cells we refer to Pacilly et al. (2018).

In the model farmers select one of four late blight management strategies for their field (Table A.1). Farmers can choose between a susceptible or late blight resistant potato variety with or without the use of fungicides. These strategies have different effects on field and landscape performance. Field performance was analysed for criteria including yield, income and infection level. To calculate farmers' income the crop price $\left(p_{m}\right)$ was set at $€ 13$ per $100 \mathrm{~kg}^{-1}$ and the fungicide costs $\left(f_{c}\right)$ at $€ 50$ per application. For the decision making processes we used behavioural strategies according to the Consumat approach (Jager and Janssen, 2012; Jager et al., 2000; Janssen and Jager, 2001). To evaluate their field performance farmers calculate the actual, estimated (predicted) and potential performance per criterion. These results are used to determine farmers satisfaction and uncertainty levels which leads to one of the following behavioural strategies: repeating, imitating, optimizing and social-comparison (Figure A.1). The decision making process is influenced by personal characteristics including farmers need satisfaction and uncertainty tolerance level. We distinguish four farmer types in the model which differ in the weights assigned to the criteria (Table 1). Weights represent farmer preferences related to the criteria infection level, yield and income.

Processes on crop growth and disease dynamics are simulated at grid cell level. The grid cells are characterised by location, field number, potato variety (susceptible or resistant), fungicide use and variables and parameters for crop growth and late blight infection (Pacilly et al., 2018). We consider only one type of susceptible and resistant variety (with one resistance gene). We assume the resistant variety has a $20 \%$ lower potential yield compared to the susceptible variety, which is reflected in the crop growth parameters. Two types of late blight are distinguished in the model: the wild-type and the virulent strain. The wild-type can only infect the susceptible variety, while a virulent strain can also infect the resistant variety. At the start of the simulation only the wild-type is present. The virulent strain can emerge during the growing season as the result of mutation. To simulate disease dispersal we used an aged-structured population model (Skelsey et al., 2010). When spores germinate lesions first enter a latent phase of five days after which they become infectious and produce spores. After the infectious phase, lesions are added to the pool of no longer infectious tissue. A fraction of the produced spores is dispersed by wind to nearby cells where they can cause infections. Since late blight development and crop growth is weather dependant, we used measured weather data as input for the model. 
Table A.2. Overview of farmer variables and parameters. For each farmer the parameters were randomly selected based on a mean value $(\mu)$ or within a range (see also Table 1 ).

\begin{tabular}{|c|c|c|}
\hline Symbol & Description (unit) & Value \\
\hline \multicolumn{3}{|c|}{ Farmer parameters } \\
\hline FS & Field size (ha) & $\mu=7$ \\
\hline $\mathrm{L}$ & Network links (no) & $\mu=5$ \\
\hline $\mathrm{F}_{\mathrm{t}}$ & Farmer type (-) & $1-4$ \\
\hline $\mathrm{U}_{\mathrm{f}}$ & Uncertainty tolerance level (-) & $0-1$ \\
\hline $\mathrm{S}_{\mathrm{f}}$ & Need satisfaction (-) & $0-1$ \\
\hline$w_{d}$ & Weight of infection level criterion (-) & $0-1$ \\
\hline$w_{p}$ & Weight of income criterion (-) & $0-1$ \\
\hline$w_{y}$ & Weight of yield criterion (-) & $0-1$ \\
\hline \multicolumn{3}{|c|}{ Farmer variables } \\
\hline BS & Behavioural strategy (-) & \\
\hline MS & Management strategy (-) & \\
\hline$f_{n}$ & Fungicide applications (mean no year ${ }^{-1}$ ) & \\
\hline$e_{d}$ & Estimated infection level (-) & \\
\hline$e_{p}$ & Estimated income $\left(€ \mathrm{ha}^{-1}\right)$ & \\
\hline$e_{y}$ & Estimated yield (tonnes ha-1) & \\
\hline$a_{d}$ & Actual infection level (-) & \\
\hline$a_{p}$ & Actual income $\left(€\right.$ ha-1 $\left.^{-1}\right)$ & \\
\hline$a_{y}$ & Actual yield (tonnes ha-1) & \\
\hline$p_{d}$ & Potential infection level (-) & \\
\hline$p_{p}$ & Potential income $\left(€\right.$ ha $\left.^{-1}\right)$ & \\
\hline$p_{y}$ & Potential yield (tonnes ha-1) & \\
\hline$S_{d}$ & Infection level satisfaction (-) & \\
\hline$S_{p}$ & Income satisfaction (-) & \\
\hline $\mathrm{S}_{\mathrm{y}}$ & Yield satisfaction (-) & \\
\hline $\mathrm{S}_{\mathrm{t}}$ & Total satisfaction (-) & \\
\hline$U_{d}$ & Infection level uncertainty (-) & \\
\hline$U_{p}$ & Income uncertainty (-) & \\
\hline $\mathrm{U}_{\mathrm{y}}$ & Yield uncertainty (-) & \\
\hline $\mathrm{U}_{\mathrm{t}}$ & Total uncertainty (-) & \\
\hline
\end{tabular}

\section{A.3 Process overview and scheduling}

The time step in the model is one day and we simulate the potato growing season from May 1 to September 30 for 50 years. Processes in the model include (Figure A.2): 1) Crop growth and disease dynamics (grid cells), 2) Update field performance (farmers), 3) Calculate relative satisfaction and uncertainty (farmers), 4) Select behavioural strategy (farmers), 5) Select management strategy (farmers) and 6) Predict field performance (farmers). Processes on crop growth and late blight dispersal are updated on a daily step. Decision-making processes of farmers ( 2 to 6$)$ are executed at the end of the growing season. Within each submodel grid cells and agents are processed in a random order. A detailed description of model processes can be found in Section A.7. 


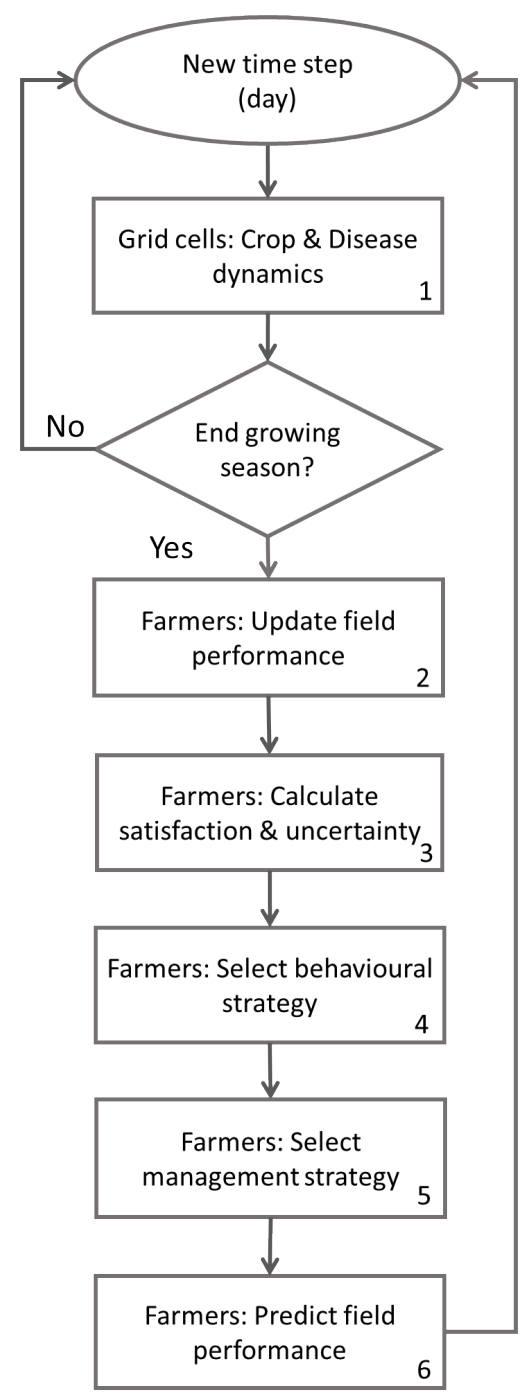

Figure A.2. Flow chart of the model processes focussing on farmers' decision making.

\section{A.4 Design concepts}

\section{Basic principles}

The model is a spatial representation of the social-ecological system of potato late blight management. We focus on the interactions and feedbacks mechanisms between farmers' decision making and disease dynamics in an agricultural landscape. For the epidemiological processes we used the previously developed model (Pacilly et al., 2018) and we added a social dimension of decision making on late blight control. The framework on farmers' decision making was based on the Consumat approach (Jager and Janssen, 2012; Janssen and Jager, 2001) and results from interviews with Dutch potato farmers (Pacilly et al., 2016). 


\section{Emergence}

Both social and ecological dynamics are emerging from the model as a result of interactions between farmers' decision-making and disease dynamics including: farmers behavioural strategies, farmers late blight management strategies, field performance for the criteria infection level, yield and income and disease dispersal at landscape level.

\section{Adaptation}

During the simulation farmers can change their late blight management strategy. Four late blight management strategies are implemented in the model (Table A.1). At the end of each year farmers analyse their field performance and based on the results for the criteria on infection level, yield and income their satisfaction and uncertainty is calculated. According to the Consumat approach one of four behavioural strategies is selected (Figure A.1): repetition, imitation, social comparison and optimisation. Based on their behavioural strategy farmers continue using the same late blight management strategy or select one of the other three strategies (see Section A.7 for more details).

\section{Objectives}

When farmers are unsatisfied and/or uncertain one of the following behavioural strategies is selected according to the Consumat approach: imitation, social comparison and optimisation. In the case of social comparison and optimisation farmers aim to select a management strategy that results in a higher satisfaction by improving their field performance related to the criteria infection level, yield and income.

\section{Prediction}

Based on observed results farmers predict their field performance (expected values) for the three criteria: infection level, yield and income. The expected values are calculated by taking the mean value using historical values of their own field of the last five years.

\section{Sensing}

Farmers can sense the field performance of the farmers in their network as well as their late blight management strategy. In the case of optimising behaviour farmers have information about the mean field performance per management strategy of the last growing season. 


\section{Interaction}

Agents interact by sensing the state variables of other agents in their network. Secondly, the field performance of farmers is affected by the management strategies of other farmers in the landscape as a result of spatial interactions related to disease dispersal.

\section{Stochasticity}

At the start of the simulation the landscape is initialised in which farmers and potato fields are randomly allocated in the landscape. Management strategies are randomly divided over the farmers. Secondly, for a number of farmer characteristics the values are randomly selected to create a heterogeneous population including: the number of contacts (links), uncertainty tolerance level (0-1), need satisfaction (0-1) and farmer type. Farmer types differ in the weights which represent farmer preferences for the different criteria (Table 1). With respect to disease processes, at the start of each year the infection is initialised in a fraction of the potato grid cells, randomly selected. Weather data is used as input for the model and each year data of one year is selected from a dataset of 36 years. During the growing season spores are dispersed by wind and every time step the wind direction is randomly selected (northeast, southeast, southwest and northwest).

\section{Collectives}

Each field is a collective of one or more grid cells which is managed by a farmer. Farmers select a management strategy for their field and they evaluate their field performance by using the mean value of the grid cells belonging to the field.

\section{Observation}

At the end of each year data on landscape level was recorded including behavioural strategies and management strategies of farmers as well as variables related to disease dispersal in the landscape. Secondly the mean performance of each management strategy was calculated for the criteria infection level, yield and income. In the model interface several graphs are presented to observe the output over time.

\section{A.5 Initialization}

The model represents an agricultural landscape of $10 \mathrm{~km} \times 10 \mathrm{~km}$ with a potato density of $\pm 24 \%$. The model consists of $50 \times 50$ grid cells which represent a squared area of $200 \mathrm{~m} \times 200 \mathrm{~m}$. At the start of the simulation the landscape is initialised with 350 farmers that each manage one potato field with a mean size of 7 ha. These parameters were derived from landscape data of a Dutch agricultural region. A network is initialised in which farmers are connected to the closest farmers around them, 
with a mean number of 5 links per farmers. At the start of the simulation we assume that all farmers grow a susceptible variety and the majority applies fungicides ( $90 \%$ of the farmers). Before the actual simulation started, the model was first run for five years without decision-making processes of farmers to create a list of reference values related to farmers' field performance. An overview of initial values of crop growth and late blight can be found in Pacilly et al. (2018). To create a heterogeneous population farmer characteristics were selected randomly (See Table 1 and Section A.4 Stochasticity).

\section{A.6 Input data}

Meteorological data was used as input for the model to simulate crop growth and late blight dispersal during the growing season (May 1 to September 30). Data from two Dutch weather stations was used: Eelde (1981-1993) and Marknesse (1994-2016). In this way a dataset of 36 years of weather data was created. Mean daily temperature and total radiation was calculated and used to simulate crop growth. Secondly, based on calculation rules using hourly temperature and humidity during a 24-hour period, we determined if a day was suitable for sporangia to cause infection (Skelsey et al., 2009). On a so-called 'blight day' newly produced spores can cause infections as a result of spore germination. See Pacilly et al. (2018) for more details.

\section{A.7 Submodels}

Below the model procedures as shown in Figure A.2 are described in more detail.

1. Crop and disease dynamics (grid cells): At the start of each year late blight infections are initialised in a fraction of the potato fields, randomly selected. During the growing season (May till September), processes related to crop growth and disease dynamics are simulated with a daily time step. According to governmental regulations the potato haulm is destroyed when the disease severity in a field reaches $5 \%$. As a result crop growth stops directly and the disease can no longer disperse to other fields. For a detailed description of these model processes we refer to Pacilly et al. (2018).

2. Update field performance (farmers): At the end of each year the actual and potential field performance is determined for farmers for each performance criterion (i): infection level, yield and income.

a. Actual field performance

i. Yield $\left(a_{\mathrm{y}}\right)$ : The mean potato yield is calculated (tonnes per ha) which is affected by the potato variety, weather conditions and infection with late blight. 
ii. Income $\left(a_{p}\right)$ : Income $\left(€ h a^{-1}\right)$ is based on the actual yield and the price for potatoes minus costs for fungicide application (Equation A.1). The crop price $\mathrm{P}_{t}$ is set at $€ 13$ per $100 \mathrm{~kg}^{-1}$. This value was derived from a dataset on potato prices in the Netherlands from 2000 to 2017 (WUR, 2018). For the susceptible and resistant varieties the same value is used. Costs for fungicides are related to the mean number of applications $\left(f_{n}\right)$ and the costs per application $\left(f_{c}\right)$, set at $€ 50$. $a_{p}=a_{y} * P_{t} * 10-f_{n} * f_{c}$

iii. Infection level $\left(a_{d}\right)$ : to analyse the infection level a scale from 1 to 4 was developed using results on disease severity (the percentage of infected leaf tissue), where high values represent a high disease severity: $1:<0.1 \%, 2: 0.1-1 \%$, 3: $1-5 \%, 4:>5 \%$.

b. The potential performance is the maximum result which could be achieved in a specific year without any losses caused by the disease.

i. Potential yield $\left(p_{y}\right)$ is determined by calculating the maximum yield that could be achieved for susceptible and resistant fields based on the weather conditions in that year (temperature and radiation).

ii. The potential income $\left(p_{p}\right)$ is calculated in the same way as the actual income but using the potential yield (Equation A.2).

$$
\boldsymbol{p}_{\boldsymbol{p}}=\boldsymbol{p}_{\boldsymbol{y}} * \boldsymbol{P}_{\boldsymbol{t}} * \mathbf{1 0}-\boldsymbol{f}_{\boldsymbol{n}} * \boldsymbol{f}_{\boldsymbol{c}}
$$

iii. The potential infection level was set at 1 for all management strategies which represents no or a very low infection level.

3. Calculate relative satisfaction and uncertainty (farmers): Farmers calculate the relative uncertainty and satisfaction for each performance criterion (i). The overall uncertainty and satisfaction is influenced by the weights. Weights represent farmer preferences for the different criteria.

a. Satisfaction is defined as the ratio between the actual field performance $\left(a_{i}\right)$ and the potential field performance $\left(p_{i}\right)$ for each performance criterion (i). The total satisfaction is based on the satisfaction level for each criterion and their weights ( $\left.w_{i}\right)$ (Equation A.3).

$\boldsymbol{S}_{\boldsymbol{t}}=\sum \boldsymbol{w}_{\boldsymbol{i}} \boldsymbol{a}_{\boldsymbol{i}} / \boldsymbol{p}_{\boldsymbol{i}}$

b. Uncertainty is defined as the ratio between the actual field performance and the estimated value $\left(e_{i}\right)$. The total uncertainty is based on the uncertainty for each criterion (i) influenced by the weights (Equation A.4).

$U_{t}=\sum w_{i} a_{i} / e_{i}$ 
4. Select behavioural strategy (farmers): Farmers compare their relative satisfaction and uncertainty level $\left(S_{t}\right.$ and $\left.U_{t}\right)$ to their personal need satisfaction $\left(S_{f}\right)$ and uncertainty tolerance level $\left(U_{f}\right)$. Based on the Consumat framework farmers select one of four behavioural strategies (Figure A.1):

a. If unsatisfied and uncertain $\left(\mathrm{S}_{\mathrm{t}}<\mathrm{S}_{\mathrm{f}}\right.$ and $\left.\mathrm{U}_{\mathrm{t}}<\mathrm{U}_{\mathrm{f}}\right)$ : Social comparison

b. If unsatisfied and certain $\left(\mathrm{S}_{\mathrm{t}}<\mathrm{S}_{\mathrm{f}}\right.$ and $\left.\mathrm{U}_{\mathrm{t}}>\mathrm{U}_{\mathrm{f}}\right)$ : Optimisation

c. If satisfied and uncertain $\left(\mathrm{S}_{\mathrm{t}}>\mathrm{S}_{\mathrm{f}}\right.$ and $\left.\mathrm{U}_{\mathrm{t}}<\mathrm{U}_{\mathrm{f}}\right)$ : Imitation

d. If satisfied and certain $\left(S_{t}>S_{f}\right.$ and $\left.U_{t}>U_{f}\right)$ : Repetition

5. Select management strategy (farmers): According to their behavioural strategy farmers select a management strategy.

a. Social comparison: Farmers select the criterion they want to improve: infection level, yield or income. Therefore farmers compare the results of their field for each performance criterion (i) by calculating the weighted satisfaction $\left(\mathrm{O}_{\mathrm{i}}\right)$ which is based on the satisfaction level and the weights) (Equation A.5).

$\boldsymbol{O}_{i}=S_{i}\left(1-w_{i}\right)$

The criterion with the lowest score is selected by farmers which represents the criterion they want to optimize. For this criterion, farmers compare the performance of the other farmers in their network and take over the management strategy of the farmer with the best result.

b. Optimisation: Farmers select the criterion they want to optimize similar to social comparison. Farmers compare the mean performance of all four management strategies based on the results of the previous year and adopt the management strategy that has the best result for the criterion the farmer wants to optimize. If management strategies were not used by farmers the results of the previous year are used. Since the management strategies including the resistant variety with and without fungicides are not used by farmers at the start of the simulation, the potential values are used which represents the mean field performance of these two strategies. When the resistant variety with and without fungicides have the same highest score it is assumed that farmers select the resistant variety without fungicides.

c. Imitation: Farmers adopt the management strategy which is used by the majority of farmers in their network. If this includes two or more strategies one of these strategies is randomly selected.

d. Repetition: Farmers don't change their management strategy. 
6. Predict field performance (farmers): Farmers estimate the value $\left(\mathrm{e}_{\mathrm{i}}\right)$ for each performance criterion (i) for the coming year. Therefore they calculate the mean value using historical values of their own field of the last five years.

\section{Appendix B Results alternative network structure}

Table B.1. Year of resistance breakdown as a result of establishment of the virulent strain. The effect of farmer network structure was analysed. Standard settings: Mean number of links per farmer $=5$ and farmers are connected to the closest farmers around them (shortest distance), Higher number of links: Mean number of links per farmer $=10$ and farmers are connected to the closest farmers around them, Connecting farmer types: Mean of links per farmer $=5$ and farmers are connected to the closest farmers around them of the same farmer type. For each scenario the model was run for 100 times.

\begin{tabular}{lrrrrrrr}
\hline & \multicolumn{7}{c}{$\begin{array}{c}\text { Year resistance breakdown } \\
\text { (percentage of runs) }\end{array}$} \\
Network structure & $\mathbf{0 - 1 0}$ & $\mathbf{1 0 - 2 0}$ & $\mathbf{2 0 - 3 0}$ & $\mathbf{3 0 - 4 0}$ & $\mathbf{4 0 - 5 0}$ & $>\mathbf{5 0}$ \\
\hline Standard settings & 41 & 17 & 5 & 4 & 6 & 27 \\
Higher number of links & 41 & 14 & 5 & 2 & 10 & 28 \\
Connecting farmer types & 44 & 14 & 10 & 4 & 6 & 22 \\
\hline
\end{tabular}

Table B.2. Management strategies of farmers (\%) at the end of the simulation (year 50) in case resistance breakdown occurs and in case the resistance remains effective. The effect of farmer network structure was analysed. Standard settings: Mean number of links per farmer $=5$ and farmers are connected to the closest farmers around them (shortest distance), Higher number of links: Mean number of links per farmer $=10$ and farmers are connected to the closest farmers around them, Connecting farmer types: Mean of links per farmer $=5$ and farmers are connected to the closest farmers around them of the same farmer type. Mean values are shown ( $\pm S D$ ) based on 100 runs.

\begin{tabular}{lcccr}
\hline Network structure & \multicolumn{4}{c}{ Management strategies of farmers (\%) } \\
& Sus- & Sus+ & Res- & Res+ \\
\hline Resistance breakdown occurs & & & & \\
Standard settings & $0.9 \pm 0.7$ & $92.0 \pm 3.7$ & $0.2 \pm 1.4$ & $6.9 \pm 3.5$ \\
Higher number of links & $0.9 \pm 0.6$ & $91.8 \pm 3.6$ & $0.2 \pm 1.2$ & $7.0 \pm 3.6$ \\
Connecting farmer types & $1.0 \pm 0.9$ & $89.3 \pm 5.0$ & $0.6 \pm 3.2$ & $9.1 \pm 4.6$ \\
Resistance remains effective & & & & \\
Standard settings & $0.6 \pm 0.6$ & $79.0 \pm 2.4$ & $19.5 \pm 3.1$ & $1.0 \pm 1.9$ \\
Increasing the number of links & $0.7 \pm 0.7$ & $79.3 \pm 3.4$ & $19.7 \pm 3.0$ & $0.3 \pm 0.6$ \\
Connecting farmer types & $0.4 \pm 0.4$ & $74.2 \pm 3.2$ & $24.9 \pm 3.2$ & $0.5 \pm 1.2$ \\
\hline
\end{tabular}




\section{Appendix C Model initialisation: fraction of farmers growing a susceptible variety without}

\section{fungicides}

Table C.1. Year of resistance breakdown as a result of establishment of the virulent strain. The fraction of farmers growing a susceptible variety without fungicides at the start of the simulation was varied. For each parameter value the model was run 100 times.

\begin{tabular}{lrrrrrr}
\hline $\begin{array}{l}\text { Initial fraction of farmers growing a } \\
\text { susceptible variety without } \\
\text { fungicides (sus-) }\end{array}$ & $\mathbf{0 - 1 0}$ & $\mathbf{1 0 - 2 0}$ & $\mathbf{2 0 - 3 0}$ & $\mathbf{3 0 - 4 0}$ & $\mathbf{4 0 - 5 0}$ & $>\mathbf{5 0}$ \\
\hline 0.00 & 0 & 0 & 0 & 0 & 0 & 100 \\
0.05 & 32 & 9 & 7 & 4 & 3 & 45 \\
0.10 & 41 & 17 & 5 & 4 & 6 & 27 \\
0.15 & 56 & 14 & 3 & 2 & 1 & 24 \\
0.20 & 67 & 13 & 7 & 2 & 3 & 8 \\
0.25 & 76 & 8 & 6 & 1 & 1 & 8 \\
0.30 & 82 & 11 & 4 & 0 & 3 & 0 \\
\hline
\end{tabular}

Table C.2. Management strategies of farmers (\%) at the end of the simulation (year 50) in case resistance breakdown occurs and in case the resistance remains effective. The fraction of farmers growing a susceptible variety without fungicides at the start of the simulation was varied. The other farmers are growing a susceptible variety with fungicide application. Mean values are shown ( \pm SD) based on 100 runs.

\begin{tabular}{|c|c|c|c|c|}
\hline \multirow{2}{*}{$\begin{array}{l}\text { Initial fraction of farmers growing a } \\
\text { susceptible variety without } \\
\text { fungicides (sus-) }\end{array}$} & \multicolumn{4}{|c|}{ Management strategies of farmers (\%) } \\
\hline & Sus- & Sust & Res- & Res+ \\
\hline \multicolumn{5}{|l|}{ Resistance breakdown occurs } \\
\hline 0.00 & & - & - & - \\
\hline 0.05 & $0.5 \pm 0.5$ & $92.6 \pm 3.4$ & $0.1 \pm 0.5$ & $6.8 \pm 3.3$ \\
\hline 0.10 & $0.9 \pm 0.7$ & $92.0 \pm 3.7$ & $0.2 \pm 1.4$ & $6.9 \pm 3.5$ \\
\hline 0.15 & $1.1 \pm 0.6$ & $90.9 \pm 4.0$ & $0.0 \pm 0.1$ & $8.0 \pm 3.9$ \\
\hline 0.20 & $1.5 \pm 0.7$ & $90.2 \pm 3.8$ & $0.0 \pm 0.1$ & $8.3 \pm 3.7$ \\
\hline 0.25 & $1.9 \pm 0.7$ & $89.6 \pm 4.2$ & $0.0 \pm 0.2$ & $8.5 \pm 4.1$ \\
\hline 0.30 & $2.1 \pm 0.9$ & $89.1 \pm 4.0$ & $0.0 \pm 0.1$ & $8.8 \pm 4.0$ \\
\hline \multicolumn{5}{|l|}{ Resistance remains effective } \\
\hline 0.00 & $0.0 \pm 0.0$ & $81.1 \pm 2.6$ & $18.9 \pm 2.6$ & $0.0 \pm 0.0$ \\
\hline 0.05 & $0.4 \pm 0.4$ & $79.9 \pm 2.2$ & $19.5 \pm 2.3$ & $0.3 \pm 0.6$ \\
\hline 0.10 & $0.6 \pm 0.6$ & $79.0 \pm 2.4$ & $19.5 \pm 3.1$ & $1.0 \pm 1.9$ \\
\hline 0.15 & $1.0 \pm 0.5$ & $77.0 \pm 3.5$ & $20.7 \pm 4.1$ & $1.3 \pm 2.1$ \\
\hline 0.20 & $1.3 \pm 0.8$ & $75.7 \pm 3.6$ & $22.9 \pm 4.0$ & $0.2 \pm 0.4$ \\
\hline 0.25 & $1.7 \pm 1.0$ & $74.6 \pm 2.1$ & $23.4 \pm 2.2$ & $0.4 \pm 0.5$ \\
\hline 0.30 & - & - & - & - \\
\hline
\end{tabular}

\section{References}

Grimm, V., Berger, U., Bastiansen, F., Eliassen, S., Ginot, V., Giske, J., Goss-Custard, J., Grand, T., Heinz, S.K., Huse, G., Huth, A., Jepsen, J.U., Jørgensen, C., Mooij, W.M., Müller, B., Pe'er, G., Piou, C., Railsback, S.F., Robbins, A.M., Robbins, M.M., Rossmanith, E., Rüger, N., Strand, E., Souissi, S., Stillman, R.A., Vabø, R., Visser, U., DeAngelis, D.L., 2006. A standard protocol for describing individualbased and agent-based models. Ecological Modelling 198, 115-126.

Grimm, V., Berger, U., DeAngelis, D.L., Polhill, J.G., Giske, J., Railsback, S.F., 2010. The ODD protocol: A review and first update. Ecological Modelling 221, 2760-2768. 
Jager, W., Janssen, M., 2012. An updated conceptual framework for integrated modeling of human decision making: The Consumat II, paper for workshop complexity in the Real World@ ECCS, pp. 1-18.

Jager, W., Janssen, M.A., De Vries, H.J.M., De Greef, J., Vlek, C.A.J., 2000. Behaviour in commons dilemmas: Homo economicus and Homo psychologicus in an ecological-economic model. Ecological Economics 35, 357-379.

Janssen, M.A., Jager, W., 2001. Fashions, habits and changing preferences: Simulation of psychological factors affecting market dynamics. Journal of Economic Psychology 22, 745-772.

Pacilly, F.C.A., Groot, J.C.J., Hofstede, G.J., Schaap, B.F., van Bueren, E.T.L., 2016. Analysing potato late blight control as a social-ecological system using fuzzy cognitive mapping. Agronomy for Sustainable Development 36 (2), 1-18.

Pacilly, F.C.A., Hofstede, G.J., Lammerts van Bueren, E.T., Kessel, G.J.T., Groot, J.C.J., 2018. Simulating crop-disease interactions in agricultural landscapes to analyse the effectiveness of host resistance in disease control: The case of potato late blight. Ecological Modelling 378, 1-12.

Skelsey, P., Kessel, G.J.T., Rossing, W.A.H., Van Der Werf, W., 2009. Parameterization and evaluation of a spatiotemporal model of the potato late blight pathosystem. Phytopathology 99, 290-300.

Skelsey, P., Rossing, W.A.H., Kessel, G.J.T., Van Der Werf, W., 2010. Invasion of Phytophthora infestans at the landscape level: How do spatial scale and weather modulate the consequences of spatial heterogeneity in host resistance? Phytopathology 100, 1146-1161.

WUR, 2018. Prijsontwikkeling consumptieaardappelen, http://www.agrimatie.nl. 


\section{Article highlights:}

- A spatially explicit model was developed on potato late blight control

- We analysed the use of crop resistance in disease control

- We simulated the interactions between farmer behaviour and disease dynamics

- The model showed a regime shift in the control of potato late blight

- Resistance management is needed to increase resistance durability 